UNIVERSIDADE DE SÃO PAULO

FACULDADE DE MEDICINA DE RIBEIRÃO PRETO

RAFAEL LINDI SUGINO

Estudo Morfométrico da Coluna Vertebral Torácica:

Relação da transição cervicotorácica com o esterno

RIBEIRÃO PRETO

2016 
RAFAEL LINDI SUGINO

\section{Estudo Morfométrico da Coluna Vertebral Torácica: \\ Relação da transição cervicotorácica com o esterno}

Dissertação apresentada à Faculdade de Medicina de Ribeirão Preto da Universidade de São Paulo para obtenção do título de Mestre em Ciências.

Orientador: Prof. Dr. Carlos Fernando Pereira da Silva Herrero

\section{RIBEIRÃO PRETO}


Autorizo a reprodução e divulgação total ou parcial deste trabalho, por qualquer meio convencional ou eletrônico, para fins de estudo e pesquisa, desde que citada a fonte.

Sugino, Rafael Lindi

Estudo Morfométrico da Coluna Vertebral Torácica: Relação da transição cervicotorácica com o esterno - Ribeirão Preto, 2016.

65 p.: il.; $30 \mathrm{~cm}$.

Dissertação de Mestrado, apresentada à Faculdade de Medicina de Ribeirão Preto/USP. Área de concentração: Neurologia.

Orientador: Carlos Fernando Pereira da Silva Herrero.

1. Coluna Vertebral. 2. Cavidade Torácica. 3.Tomografia. 4. Esterno.

CDD 616.12 


\section{FOLHA DE APROVAÇÃO}

Rafael Lindi Sugino

\section{Estudo Morfométrico da Coluna Vertebral Torácica: Relação da transição cervicotorácica com o esterno}

Dissertação apresentada à Faculdade de Medicina de Ribeirão Preto da Universidade de São Paulo, para obtenção do título de Mestre em Ciências.

Área de concentração: Ortopedia, Traumatologia e Reabilitação do Aparelho Locomotor.

Aprovado em:

Banca Examinadora

Prof. Dr.

Instituição:

Assinatura:

Prof. Dr.

Instituição:

Assinatura:

Prof. Dr.

Instituição:

Assinatura: 
A man's friendships are one of the best measures of his worth - Charles Darwin

It always seems impossible until it is done

- Nelson Mandela 


\title{
DEDICATÓRIA
}

\author{
Dedico este trabalho
}

\section{À meu pai}

Rinji Sugino (in memoriam). A vida de meu pai foi dedicada à sua família. Agradeço por ele ter me preparado para a sua ausência, por ter me dado condições de disputar nesse mundo desigual.

\section{À minha mãe}

Alice Aiko Koga Sugino. Toda mãe esquece de si mesma para tudo dedicar aos seus filhos. O que poucas tem é a coragem de permitir que seu filho parta para ser livre, crescer, enfrentar o mundo mesmo sabendo o que a vida espera àqueles que nela se arriscam. Essas mulheres sofrem caladas, vivem na angústia, em seu próprio silêncio. Sei que você se sacrificou muito por nós. Obrigado.

\section{À minha irmã}

Patrícia Sugino. A criança frágil se tornou uma mulher forte e bem sucedida. Dando muita "sorte" e cabeçada na vida, vamos melhorando aos poucos. Ainda temos muito o que fazer e você sabe que se pararmos para ficamos nos lamentando ou perdidos na vida, Sr. Rinji desce para fazer mais um de seus sermões repetitivos e intermináveis, com um toque de muita pouca paciência. Orgulho de minha irmã caçula. 


\section{AGRADECIMENTO ESPECIAL}

\section{Ao Professor Carlos Fernando Pereira da Silva Herrero,}

Quando uma pessoa está em uma posição de destaque, assim como é um docente de uma Faculdade de Medicina, certamente uma das melhores do Brasil, da mais importante universidade brasileira como é a USP, a pessoa é bastante observada em tudo o que faz. Em poucas palavras posso dizer que aprendi coisas que vão além da Medicina, Ortopedia, Cirurgia de Coluna, e digo que esses ensinamentos foram muito mais importantes do que o conhecimento puramente técnico. Algumas qualidades facilmente observadas são sua atenção e cuidado com os pacientes e àquela busca incessante pela excelência na profissão. Tais características não são somente elogios, uma vez que sem elas seria pouco provável que estaria na posição em que se encontra.

Agradeço também a oportunidade de completar esta dissertação, pelo tempo gasto nela e em reuniões, por compreender as dificuldades que eu como aluno de mestrado sem grandes experiências com publicações poderia apresentar, pela paciência em ajudar a resolver os problemas que encontrei durante o trajeto e especialmente por muitas vezes fazer mais do que simplesmente orientar, tendo uma postura muito ativa para a conclusão do trabalho.

\section{Ao Professor Helton Luiz Aparecido Defino e família,}

Agradeço ao Professor Helton e sua família por esses dois anos de amizade e ensinamentos. Não posso deixar de comentar a grande oportunidade que tive de ouvir as suas muitas histórias de vida e entender que não existe caminho fácil para o sucesso além de vivenciar a luta diária que enfrenta para manter um trabalho de excelência no Hospital das Clínicas. De minha parte foi um grande prazer e uma excelente experiência ter trabalhado por 2 anos ao lado de uma pessoa bastante sábia. Agradeço também à Silvia, à Patrícia e ao Matheus pela amizade e muitas risadas. 


\section{AGRADECIMENTOS}

Aos meus amigos e pessoas que me apoiaram.

Aos amigos Herton Rodrigues Tavares Costa, Narcélio Mendes, Bruno Ancheschi, Mario Bressan Neto e Anderson Luis Nascimento pela época de Fellow em coluna.

Aos meus amigos residentes e ex-residentes da Ortopedia, atuais ou futuros colegas ortopedistas pela amizade, histórias, plantões e risadas.

Ao Prof. Dr. Marcello Henrique Nogueira Barbosa pela ajuda durante os dois anos de residência e também pela ajuda nesta dissertação

Ao Prof. Marcelo Riberto pela ajuda, conversas, aprendizados e amizade, além de bastante ter ajudado nessa dissertação.

Aos Docentes e contratados da Ortopedia do HCRP, que muito me ensinaram nestes anos de Ribeirão Preto.

Aos técnicos de gesso do Ambulatório de Ortopedia do Hospital das Clínicas da Faculdade de Medicina de Ribeirão Preto da Universidade de São Paulo: Ezequiel Libório de Godoy, Agenor dos Santos, Antônio Eurípedes Faleiros e aos funcionários do Ambulatório de Ortopedia do HCRP, pelo apoio e convivência.

Aos meus colegas de pós-graduação pela convivência e amizade.

E a todos que, direta ou indiretamente, contribuíram para a realização deste trabalho. 


\title{
RESUMO
}

\author{
SUGINO, R. L. Estudo morfométrico da coluna vertebral torácica: Relação da transição \\ cervicotorácica com o esterno. 2016. 65 fs. Dissertação (Mestrado) - Faculdade de Medicina \\ de Ribeirão Preto, Universidade de São Paulo, Ribeirão Preto, 2016.
}

A transição cervicotorácica compreende a região anatômica que envolve as vértebras cervicais distais e as torácicas proximais. Durante a realização de abordagens cirúrgicas anteriores para tratamento de afecções que acometem as vértebras desta região, o esterno pode representar uma barreira mecânica. Assim, diversos métodos de programação pré-operatório foram propostos para avaliar a necessidade de osteotomias do esterno. Até a presente data, não existem trabalhos correlacionando as medidas com as variáveis sexo e idade. Nosso estudo envolveu a avaliação retrospectiva de 300 exames de tomografia computadorizada. Os pacientes foram separados de acordo com o sexo em dois grupos e de acordo com a faixa etária em 3 subgrupos. Os parâmetros estudados foram: nível horizontal em relação ao esterno (NHE), angulação do corpo (AC), nível discal (ND) e angulação do nível discal (AND). O NHE variou de C7 a T4, sendo mais frequente o nível T2 (34,3\%). Os NHE menos frequentes foram T4 $(0,3 \%)$ e C7 (1\%). A AC e AND evidenciaram uma média de $18,51^{\circ}$ e $19,63^{\circ}$, respectivamente. O AC variou de $1,29^{\circ}$ a $54,32^{\circ}$, enquanto o AND variou de $0^{\circ}$ a $49^{\circ}$. O ND variou de C5-C6 a T2-T3, sendo C7-T1 o ND mais frequente com 46\%. O ND menos frequente foi encontrado nos níveis T2-T3 (1,7\%) e C5-C6 (3\%). Comparado o AND entre os grupos masculino e feminino, encontramos diferença estatística $(\mathrm{p}=0,003)$, sendo maior no grupo masculino. Houve diferença estatisticamente significante quando comparado os valores da AND entre os grupos etários ( $\mathrm{p}=0,01$ ). Com relação a $\mathrm{AC}$, encontramos diferença estatística entre os grupos dos sexos masculino e feminino $(\mathrm{p}=0,02)$, sendo maior no grupo masculino. A comparação do AC entre os grupos de diferentes faixas etárias demonstrou uma diferença estatística $(\mathrm{p}=0,001)$. Não houve diferença quando comparados os resultados do NHE entre os grupos masculino e feminino ( $\mathrm{p}=0,3)$, nem comparando valores de NHE entre as diferentes faixas etárias $(\mathrm{p}=0,79)$. O ND e NHE de nossa amostra da população brasileira apresenta valores menores quando comparados à outras amostras populacionais. O ND apresentou diferenças entre os grupos etários, sendo que quanto mais velho o grupo, menor eram os valores. Os nossos resultados evidenciaram que o nível discal mais distal acessível com a realização de abordagem anterior à região cervicotorácica da coluna vertebral, sem a teórica necessidade de uma osteotomia do esterno, apresenta valores menores quando comparados aos dados previamente relatados atribuídos a outras populações. Em outras palavras, este achado pode ser traduzido como se os pacientes envolvidos no estudo apresentassem um menor número de vértebras passíveis de serem abordadas por meio de procedimento cirúrgico anterior sem a realização de osteotomia do esterno. Desta forma, o mesmo raciocínio pode ser aplicado para o nível horizontal em relação ao esterno, pois nossos resultados apresentaram valores mais craniais, comparados aos resultados de estudos prévios. Além disso, o nível discal apresentou diferença quando comparamos os pacientes de diferentes faixas etárias, sendo que, quanto maior a faixa etária, menor foram os valores encontrados. Este achado representa uma migração para cranial do nível discal mais distal, conforme aumentamos a faixa etária dos pacientes estudados.

Descritores: coluna vertebral, cavidade torácica, tomografia, esterno 


\begin{abstract}
SUGINO, R. L. Morphometric study of the thoracic spine: Relationship of the cervicothoracic junction with the sternum. 2016. 65 1. Dissertation (Master) - School of Medicine of Ribeirão Preto, University of São Paulo, Ribeirão Preto, 2016.

The cervicothoracic transition comprises the anatomical region including the distal cervical and proximal thoracic vertebrae. While conducting anterior surgical approaches for treatment of conditions that affect the vertebrae in this region, the sternum may represent a mechanical barrier. Thus, various methods of preoperative programming have been proposed to assess the need for osteotomies of the sternum. To date, there are no studies correlating the measures with gender and age. Our study involved a retrospective review of $300 \mathrm{CT}$ examinations. Patients were separated according to gender into two groups and according to age into 3 subgroups. The studied parameters were: horizontal level in relation to the sternum (LHS), vertebral body angle (VA), disc level (DL) and angulation of the disc level (ADL). The LHS ranged from C7 to T4, and T2 was the most frequent (34.3\%). The less frequent LHS were T4 $(0.3 \%)$ and $\mathrm{C} 7(1 \%)$. The AC and ADL showed an average of $18,51^{\circ}$ and $19,63^{\circ}$ respectively. The VA varied $1,29^{\circ}$ the $54,32^{\circ}$, while the ADL varied from $0^{\circ}$ to $49^{\circ}$. DL ranged from C5-C6 to T2-T3, being C7-T1 the most frequent (46\%). The less frequent DL found were T2-T3 $(1.7 \%)$ and C5-C6 (3\%). Compared the ADL between male and female groups, we found statistically significant difference $(\mathrm{p}=0.003)$, being higher in the male group. There was a statistically significant difference when compared the values of ADL between the groups $(\mathrm{p}=0.01)$. Regarding VA, we found statistically significant differences between male and female groups $(p=0.02)$, being higher in the male group. Comparison of VA between groups of different age showed a statistically significant difference $(p=0.001)$. There was no difference when comparing the results of the LHS between male and female groups $(p=0.3)$, or comparing LHS values between the different age groups $(p=0.79)$. The DL and LHS in our sample of the population has lower values compared to other population samples. DL differ between age groups, and the older the group, the lower were the figures. Our results show that the most distal disc level accessible from an anterior approach to the cervicothoracic region of the spine, with no theoretical need for a sternal osteotomy, present lower values when compared to previously reported data assigned to other populations. In other words, this finding can be translated as if the enrolled patients presented fewer vertebrae that can be addressed through anterior surgical procedure without performing sternal osteotomy. Thus, the same thought can be applied to the horizontal level in relation to the sternum, since our results showed more cranial values compared to results of previous studies. In addition, the disc level was different when comparing patients of different age groups, and the higher the age, the lower were the values found. This finding represents a migration to the more distal cranial disc level, as we increase the age of the patients.
\end{abstract}

Keywords: spine, thoracic cavity, tomography, sternum 


\section{LISTA DE FIGURAS}

Figura 1 - $\quad$ O esqueleto axial: A coluna vertebral nas visões a) anterior, b) 17 lateral esquerdo e c) posterior..

Figura 2 - A vértebra cervical a) quarta vértebra cervical e b) sétima 18 vértebra cervical

Figura 3 - Vértebra Torácica a) vista superior e b) vista lateral

Figura 4 - $\quad$ Caixa Torácica (Arcabouço ósseo torácico) - vista anterior........ $\quad 20$

Figura 5 - $\quad$ Mediastino: Vista lateral esquerda .............................................. 21

Figura 6 - Mediastino: Vista lateral direita ................................................... 22

Figura 7 - Reconstrução 3D de exame de tomografia da coluna torácica com o alinhamento da reconstrução nos planos a) sagital, b) transversal e c) frontal

Figura 8 - Imagem sagital de tomografia computadorizada ilustrando o método de identificação do nível horizontal em relação ao esterno

(NHE).

Figura 9 - Imagem sagital de tomografia computadorizada ilustrando a técnica de obtenção da angulação do corpo (AC), representado por $\alpha$.......

Figura 10 - Imagem sagital de tomografia computadorizada ilustrando o método de identificação do nível discal (ND).

Figura 11 - Imagem sagital de tomografia computadorizada ilustrando o método de identificação do angulação do nível discal (AND), representado por $\beta$....... 


\section{LISTA DE TABELAS}

Tabela 1 - Parâmetros mensurados nas imagens sagitais de tomografia computadorizada ................................................................... 38

Tabela 2 - $\quad$ Conversão do parâmetro nível discal (ND) em variável ordinal ........ 43

Tabela 3 - Conversão da variável NHE em variável ordinal ............................. 43

Tabela 4 - $\quad$ Distribuição das idades e respectivos desvios padrão ....................... $\quad 45$

Tabela 5 - Tabela representando os p-valores para as variáveis AND e AC entre os diferentes sexos............................................................... 47

Tabela 6 - Tabela representando os p-valores para as variáveis AND e AC entre os diferentes grupos etários.................................................... 47

Tabela 7 - Tabela representando os p-valores para as variáveis NHE e ND

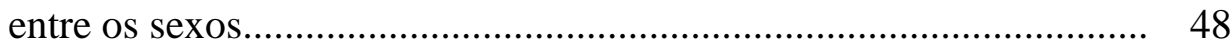

Tabela 8 - Tabela representando os p-valores para as variáveis NHE e ND entre os diferentes grupos etários..................................................... 48

Tabela 9 - Distribuição do parâmetro ND e a porcentagem de pessoas nas quais seria possível de se realizar uma cirurgia em diferentes estudos........ 


\section{LISTA DE GRÁFICOS}

Gráfico 1 - Distribuição dos resultados de NHE (por nível) em porcentagem....

46

Gráfico 2 - Distribuição dos resultados de NHE (por nível) em porcentagem.... 46

Gráfico 3 - Distribuição do parâmetro NHE e a distribuição dos casos por nível estudado e respectivo gráfico representando o mesmo

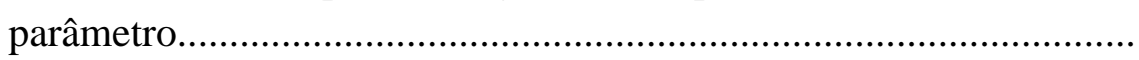




\section{LISTA DE ABREVIATURAS E SIGLAS}

ND - Nível discal

NHE - Nível horizontal em relação ao Esterno

AND - Angulação do nível discal

AC - Angulação dor corpo vertebral

IMC - Índice de massa corpórea

ATLS - Advanced Trauma Life Support

C5 - Quinta vértebra cervidal

C6 - Sexta vértebra cervical

C7 - Sétima vértebra cervical

T1 - Primeira vértebra torácica

T2 - Segunda vértebra torácica

T3 - Terceira vértebra torácica

T4 - Quarta vértebra torácica

T5 - Quinta vértebra torácica

S. Aureus - Staphylococcus Aureus 


\section{LISTA DE SÍMBOLOS}

$\% \quad$ - Porcentagem

mm - Milímitros

o - - Graus 


\section{SUMÁRIO}

1 INTRODUÇÃO............................................................................................ 16

1.1 A coluna vertebral e a caixa torácica............................................................... 17

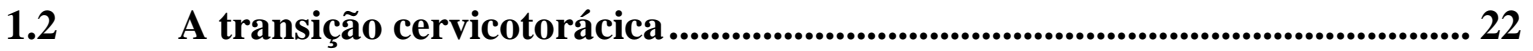

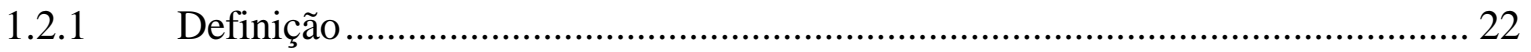

1.2.2 Patologias da transição cervicotorácica ........................................................ 23

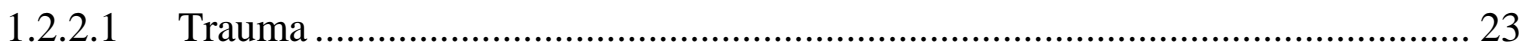

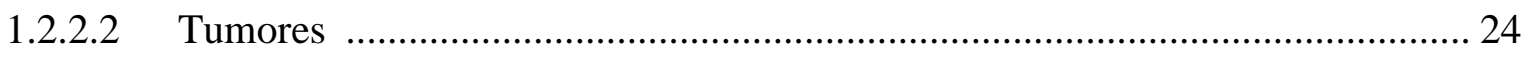

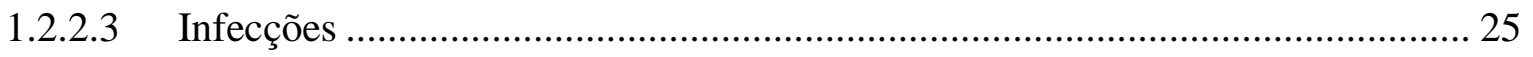

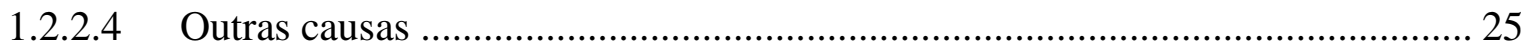

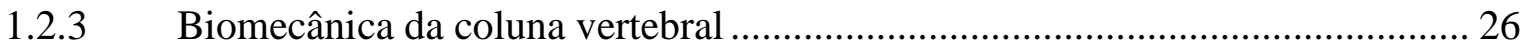

1.2.3.1 Abordgem cirurgica para o tratamento cervicotoraxica.................................... 26

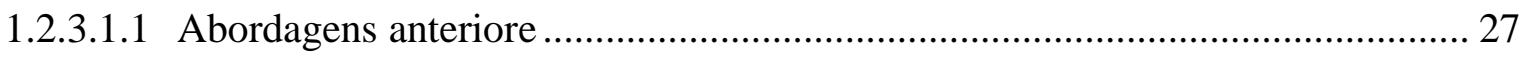

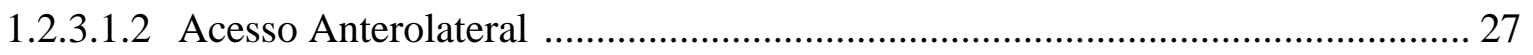

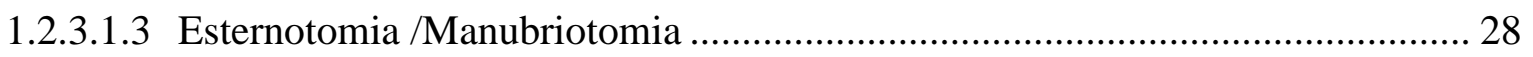

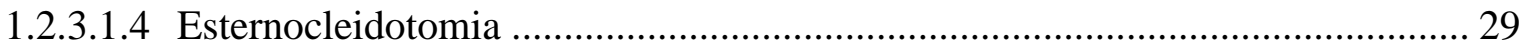

1.3 Programação cirúrgica ................................................................................................ 29

1.3.1 Métodos de programação pré-operatória …………............................................ 30

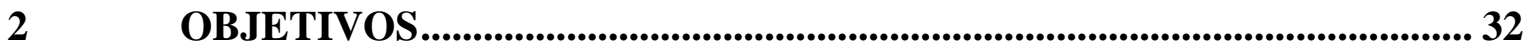

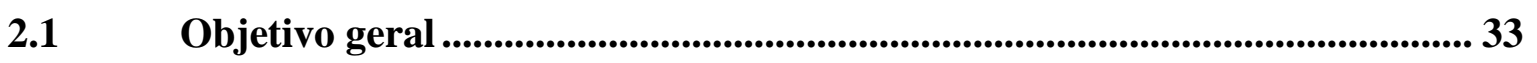

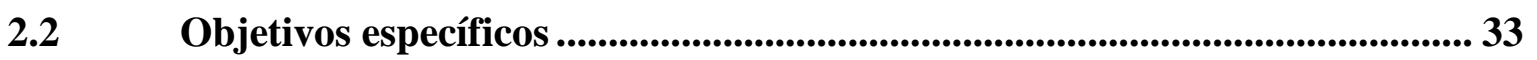

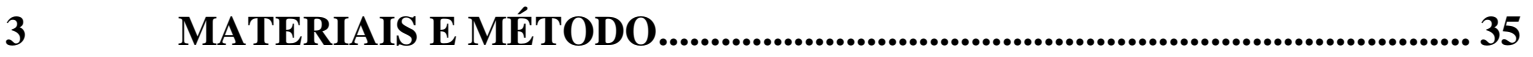

3.1 Desenho da Pesquisa ..................................................................................................... 35

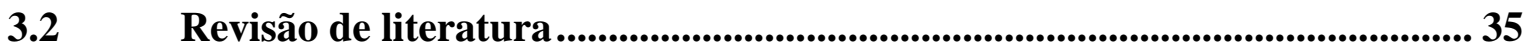

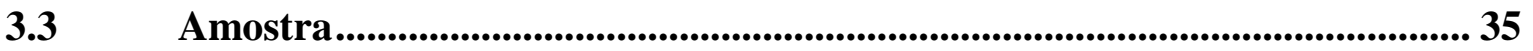

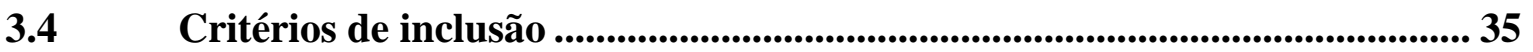

3.5 Critérios de exclusão ...................................................................................... 36

3.6 Obtenção das imagens .............................................................................. 36

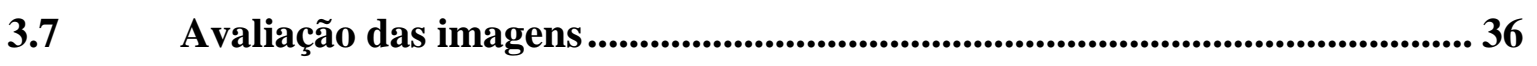

3.8 Parâmetros estudados...................................................................................... 37

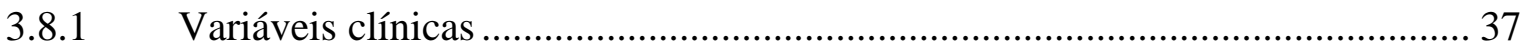

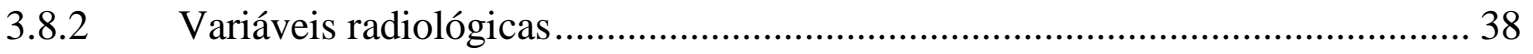




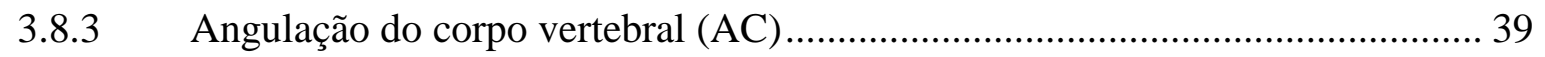

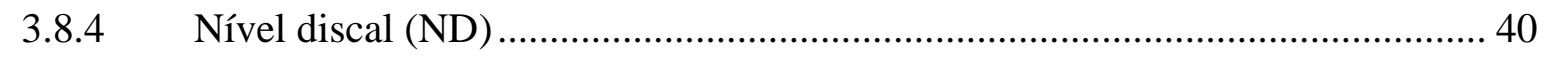

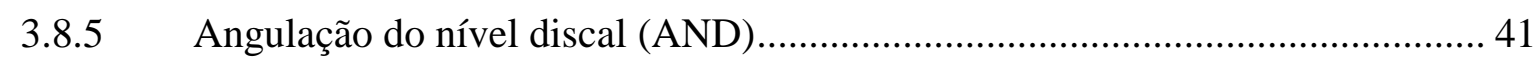

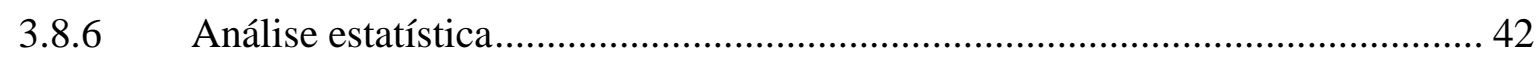

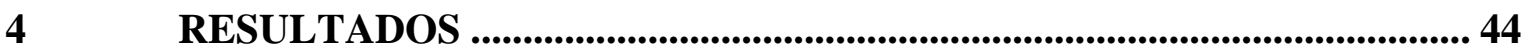

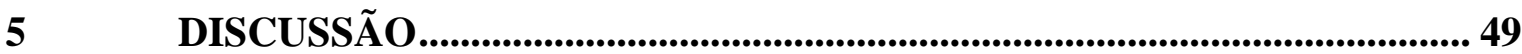

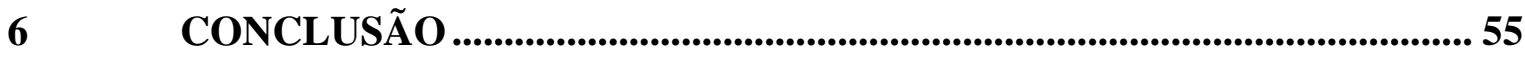

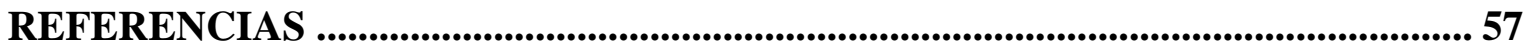

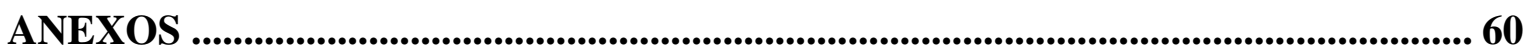

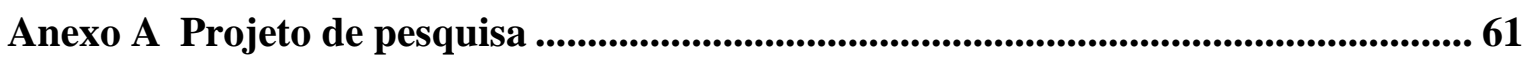

Anexo B Projeto de pesquisa ................................................................................................ 62

Anexo C Parecer consubstanciado do CEP................................................................ 63 
INTRODUÇÃO 


\section{INTRODUÇÃO}

\subsection{A coluna vertebral e a caixa torácica}

A coluna vertebral é considerada o eixo do esqueleto humano. Suas funções são proteger estruturas neurais, permitir movimento do tronco e servir de suporte à outras estruturas como músculos e ligamentos. A coluna vertebral é dividida em 4 regiões sendo estas as regiões cervical, torácica, lombar e sacrococcígea. Apesar do número de vértebras poder sofrer variações, tipicamente a coluna cervical é formada por 7 vértebras, a coluna torácica por 12 vértebras, a coluna lombar por 5 vértebras e a coluna sacrococcígea por 5 vértebras sacrais fundidas e 4 a 5 vértebras coccígeas fundidas (Figura 1).

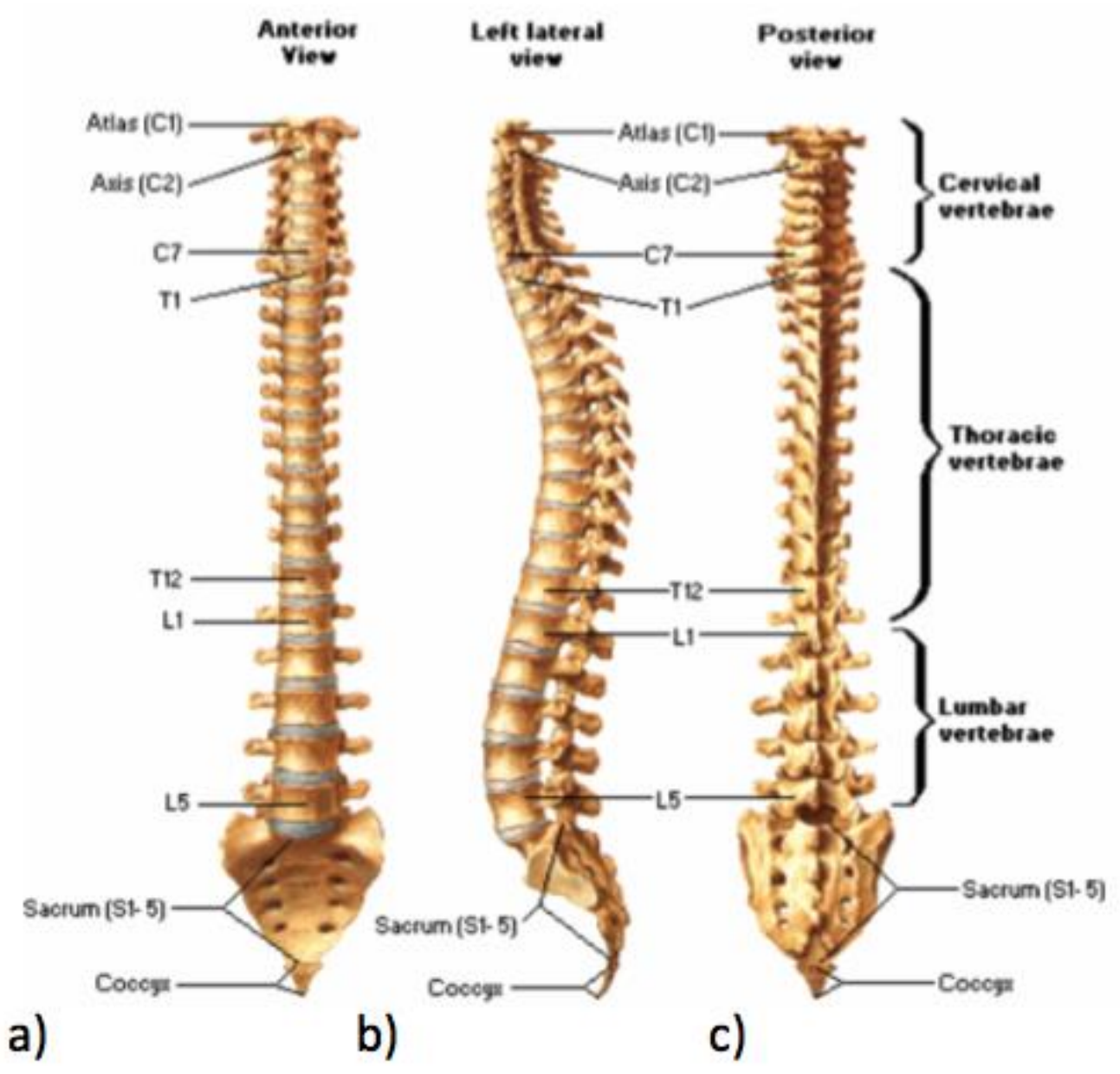

Figura 1 - O esqueleto axial: A coluna vertebral nas visões a) anterior, b) lateral esquerdo e c) posterior.

Fonte: (NETTER, 2004, p. 146). 
A região cervical é um segmento da coluna vertebral que apresenta uma interação direta com o crânio e a coluna torácica. Com exceção das duas primeiras vértebras $(\mathrm{C} 1$ e $\mathrm{C} 2)$, as características anatômicas da terceira $(\mathrm{C} 3)$ à sétima $(\mathrm{C} 7)$ vértebra cervical são semelhantes. Por serem menos requisitadas do ponto de vista biomecânico quando comparadas às vértebras torácicas e lombares, estas apresentam dimensões reduzidas e o diâmetro anteroposterior é maior quando comparado com o latero-lateral. Quando estudamos os processos espinhosos, podemos observar que os mais proeminentes são os de $\mathrm{C} 2$ e $\mathrm{C} 7$, que os processos de C3 a C6 são bífidos e que todos são direcionados para caudal e posterior, com exceção do processo espinhoso de $\mathrm{C} 7$, sendo o último reto, mais grosso e possuindo um tubérculo em sua extremidade (Figura 2).

\section{Cervical Vertebrae [C4 and C7]}

\section{Superior Views}

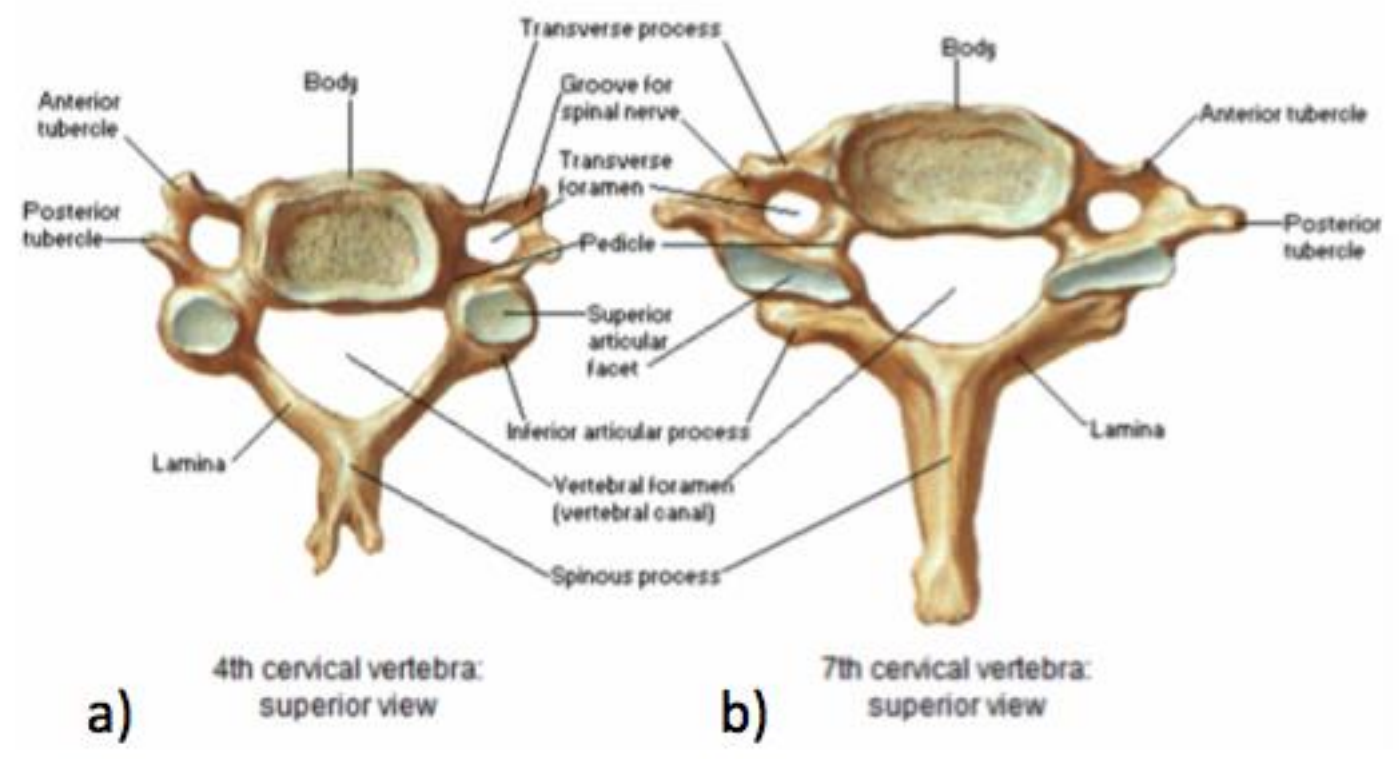

Figura 2 - A vértebra cervical a) quarta vértebra cervical e b) sétima vértebra cervical Fonte: (NETTER, 2004, p.16)

A coluna torácica é composta por 12 vértebras e 11 espaços discais. Os corpos vertebrais apresentam a forma de um coração. Suas dimensões encontram-se em um meio 
termo das colunas cervical e lombar, sendo que as vértebras proximais são semelhantes às vértebras cervicais e as distais, às lombares. Na porção anterior à esquerda pode existir achatamento do corpo vertebral devido ao contato com a artéria aorta descendente. A vértebra torácica apresenta articulações denominadas hemifacetas. A hemifacetas superior do corpo vertebral inferior juntamente com a hemifacetas inferior do corpo vertebral superior formam um ponto de apoio para uma das articulações para a costela. A outra articulação encontra-se no processo transverso, ponto de apoio da costela. O canal vertebral no segmento torácico da coluna vertebral é arredondado e pequeno em diâmetro. A faceta articular superior, ligeiramente convexa, é praticamente vertical e coronal em seu plano de articulação voltado para posterior, enquanto que a faceta articular inferior é voltada para anterior. Os processos espinhosos são alongados e com pontas triangulares (Figura 3).
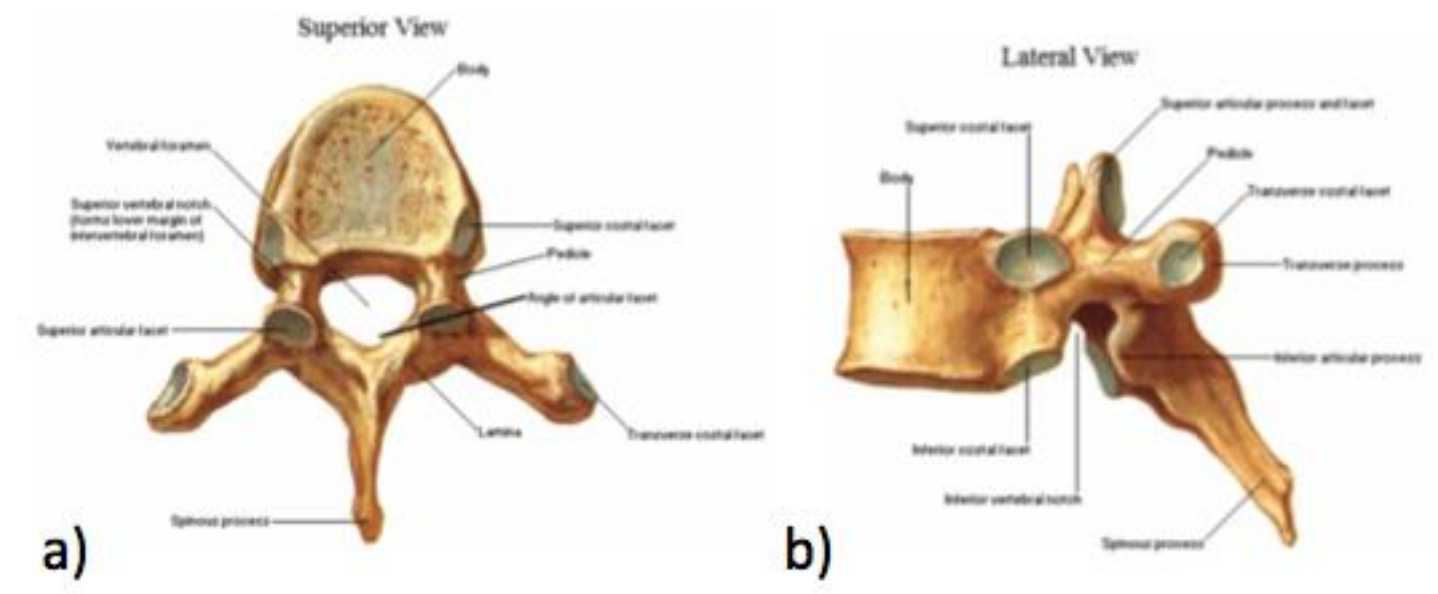

Figura 3 - Vértebra Torácica a) vista superior e b) vista lateral Fonte: (NETTER, 2004, p.147)

Anteriormente à coluna vertebral, completando a caixa torácica juntamente com os arcos costais, encontra-se o esterno. O esterno é um osso longo e achatado com forma de "T", composto por 3 partes: corpo, manúbrio e apêndice xifoide. Localiza-se na porção anterior da caixa torácica onde se articula com as clavículas e as 10 primeiras costelas de cada lado, sendo que com as 7 primeiras costelas (costelas verdadeiras) articula-se diretamente e com as 3 distais (costelas falsas) se articula liga de forma indireta após uma fusão destas em uma cartilagem. As duas últimas não se articulam, sendo assim chamadas de costelas flutuantes (Figura 4). 


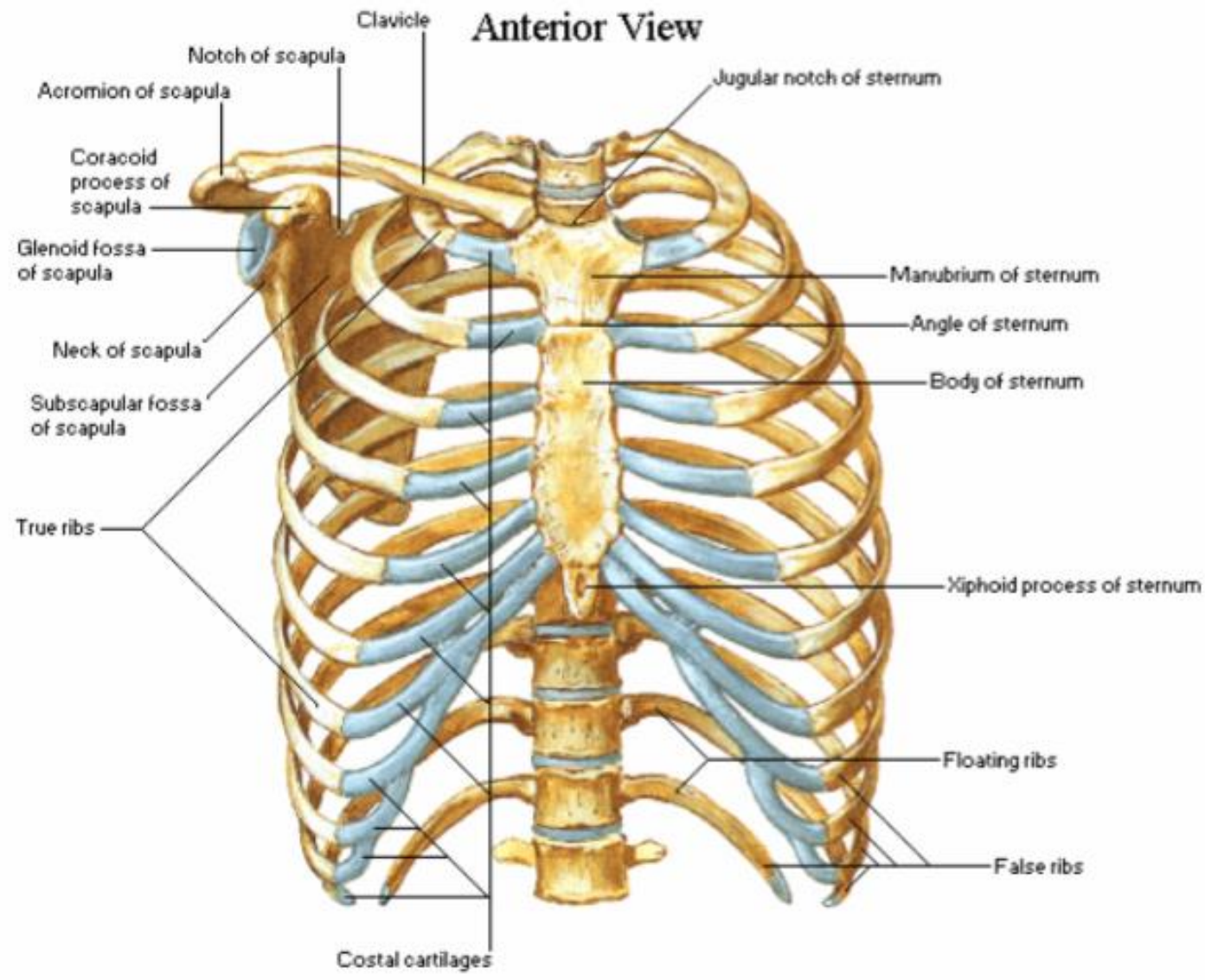

Figura 4 - Caixa Torácica (Arcabouço ósseo torácico) - vista anterior.

Fonte: (NETTER, 2004, p.178)

Denomina-se caixa torácica ou espaço torácico o espaço compreendido pelo esterno, costelas e coluna vertebral, sendo dividida em três partes: duas cavidades pleurais e uma cavidade mediastinal. As cavidades pleurais são preenchidas pelos pulmões, ocupando a maior parte da cavidade.

O mediastino é o espaço compreendido entre as regiões pleurais pulmonares. Nesta cavidade encontram-se o coração, grandes vasos, traqueia, esôfago, timo, sistema linfático e sistema nervoso autonômico. O termo grandes vasos serve para se referir coletivamente aos principais vasos sanguíneos. São eles as veias cava superior e inferior, a artéria pulmonar, as veias pulmonares e a artéria aorta (Figuras 5 e 6 ). 


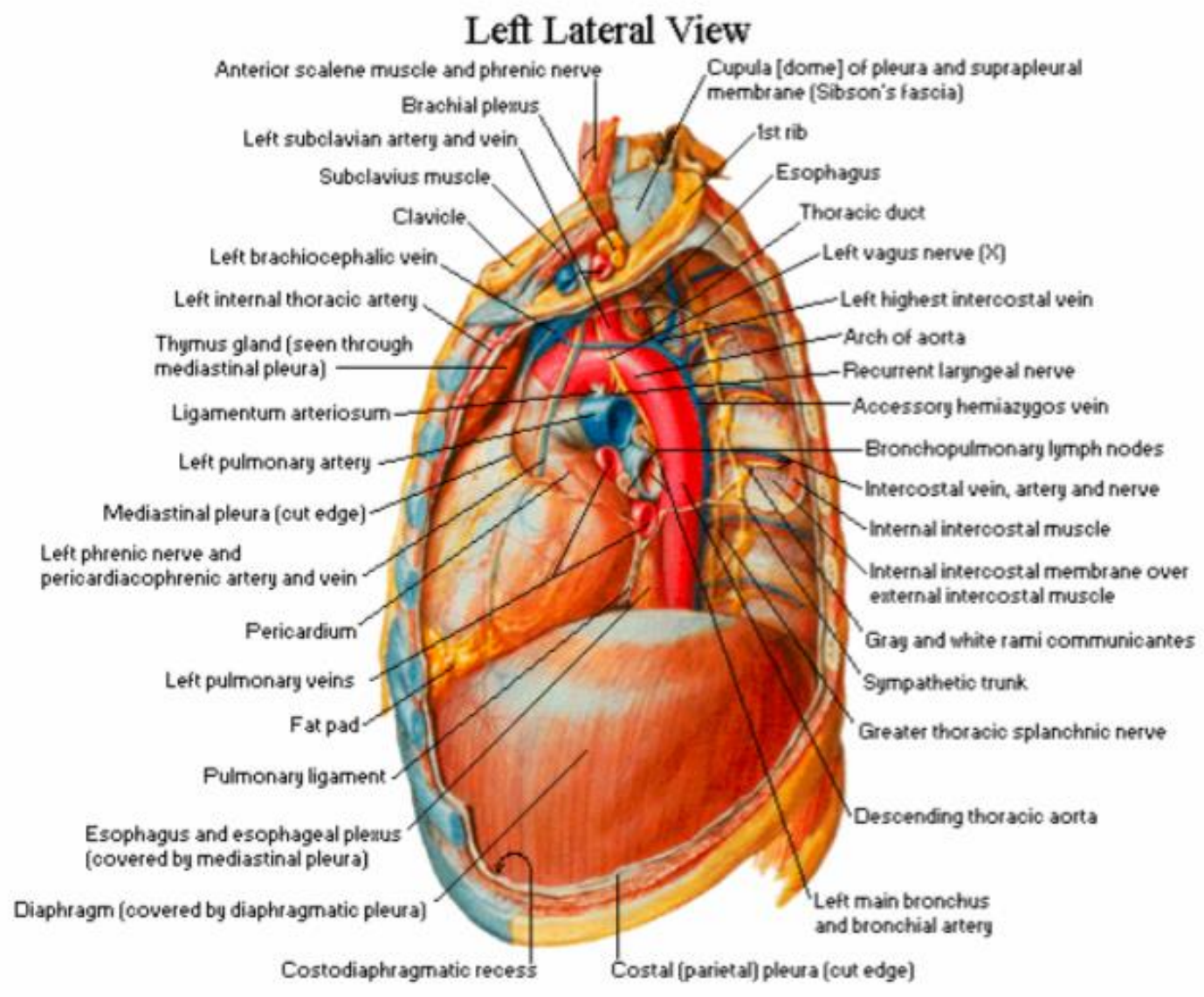

Figura 5 - Mediastino: Vista lateral esquerda

Fonte: (NETTER, 2004, p. 227) 


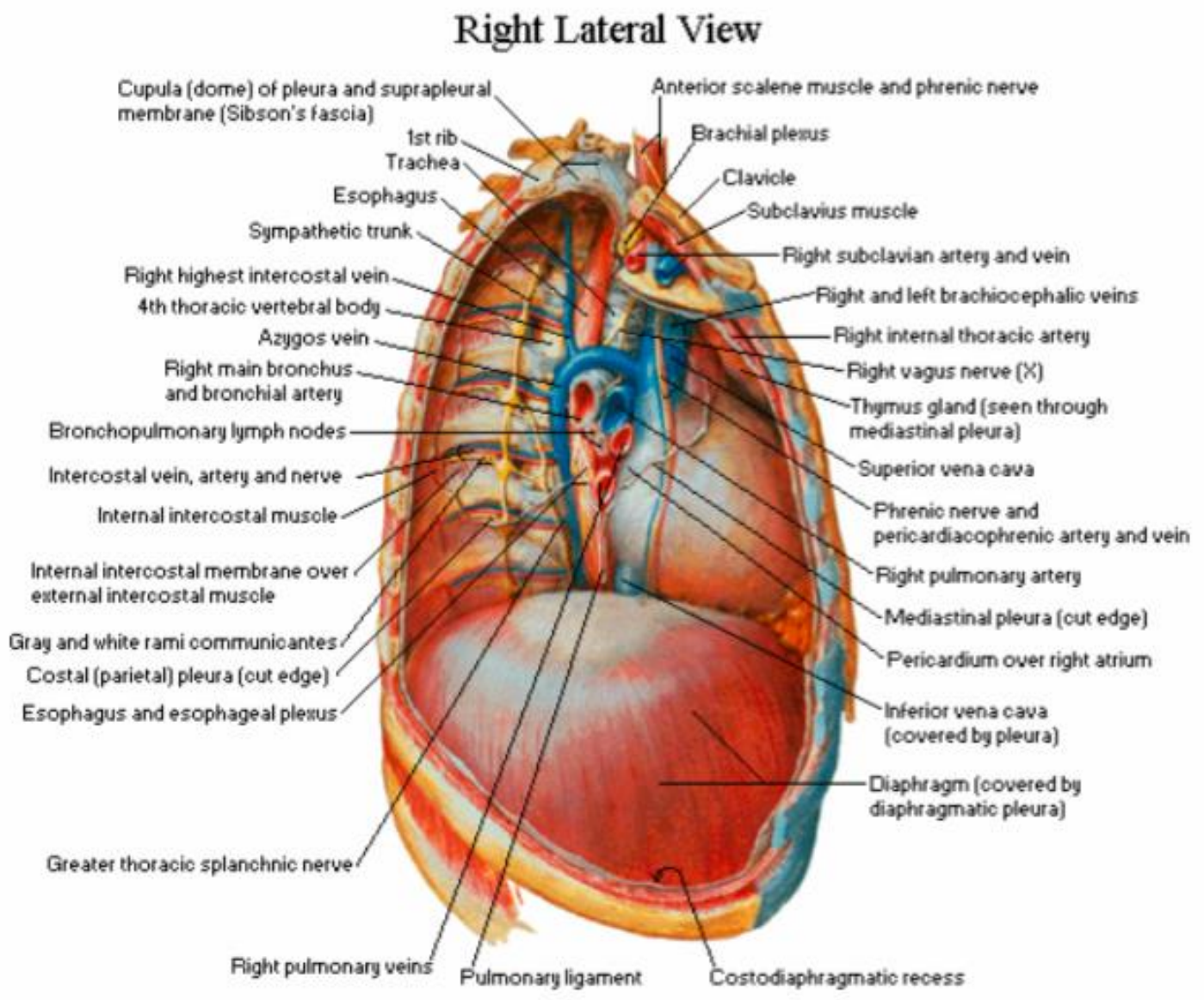

Figura 6 - Mediastino: Vista lateral direita

Fonte: (NETTER, 2004, p. 226)

\subsection{A transição cervicotorácica}

\subsubsection{Definição}

A transição cervicotorácica compreende a região anatômica que envolve as vértebras cervicais distais e as vértebras torácicas proximais, representando uma transição de uma coluna cervical móvel para uma coluna torácica rígida (CHEN; EISMONT, 2005).

O estudo desta região anatômica é de interesse de diferentes áreas: ortopedia, neurocirurgia, otorrinolaringologia e cirurgia de cabeça e pescoço. $\mathrm{O}$ acesso desta região é bastante complexo devido às importantes estruturas presentes nesta região (LE et al., 2003).

Existe grande controvérsia na literatura acerca dos limites da transição cervicotorácica. Foram propostos diferentes níveis para se determinar os limites físicos da transição cervicotorácica, sendo eles de C7 a T4 (LE et al., 2003; SIMON et al., 2004) C7 a T3 (AN et al., 1994; NICHOLS; YOUNG; SCHILLER, 1987; WANG; CHOU, 2007; PARK et al., 
2015), C7-T2 (FRASER et al., 2002) C6 a T2 (FALAVIGNA ASDRUBAL et al., 2009), C6 a T4 (BOYLE; SINGER; MILNE, 1996),C6 a T5 (KNOLLER; BRETHNER, 2002), T1 a T4 (POINTILLART et al., 2007). Existe um consenso de que esta região representa uma região de transição entre a coluna cervical em lordose e móvel, para a coluna torácica em cifose e rígida.

\subsubsection{Patologias da transição cervicotorácica}

As patologias que acometem a transição cervicotorácica podem ser de origem traumática, tumoral, infecciosa (MULPURI et al., 2005) ou outras causas menos comuns, como deformidades, doença degenerativa e doenças inflamatórias. Os estudos levantados em nossa revisão de literatura evidenciam a grande variabilidade quanto aos resultados encontrados (NICHOL; YOUNG; SCHILLER, 1987; POINTILLART et al., 2007; LE et al. 2003; HERRERO; PENNO; DEFINO, 2009).

Herrero, Penno e Defino (2009) relataram em uma série descritiva de 20 pacientes com afecções da transição cervicotorácica 45\% das patologias de origem traumática, 35\% tumoral e $20 \%$ degenerativa.

An et al. (1994) relataram em sua série que 50\% das lesões eram de origem traumática, $42 \%$ de origem tumoral, $5 \%$ de origem degenerativa e $3 \%$ abrangendo outras causas.

Segundo Pointillart et al. (2007), 81\% dos casos eram metástases, 11\% eram tumores primários, 5\% eram lesões traumáticas e 3\% infecções. Sapkas et al. (1999) apresentaram sua série de 10 casos, $60 \%$ de traumas, 30\% de metástases e 10\% de lesões primárias malignas.

Le et al. (2003) descrevem em seus 46 casos uma porcentagem de $41 \%$ de tumores, $33 \%$ de fraturas, $4 \%$ de infecção e $22 \%$ de processos degenerativos. Falavigna Asdrubal et al. (2009) encontraram em sua série de casos $7 \%$ infecções, $7 \%$ fraturas, $29 \%$ degenerativo e $57 \%$ lesões tumorais.

\subsubsection{Trauma}

A incidência de trauma na região cervicotorácica varia de 2 a $9 \%$ de todas as fraturas da coluna cervical (NICHOLS; YOUNG; SCHILLER, 1987; WANG; CHOU, 2007), com a maioria dos trabalhos reportando uma incidência de 2 a $5 \%$ na região. No entanto, quando comparada a outras regiões da coluna torácica, existe uma alta probabilidade de dano neurológico nas lesões da transição cervicotorácica da coluna vertebral, podendo variar de 59 a 83\% segundo a literatura (NICHOLS; YOUNG; SCHILLER, 1987; AN et al., 1994). 
De acordo com estudos prévios, nos casos de trauma da transição cervicotorácica a lesão inicial não é diagnosticada na admissão hospitalar em cerca de $27 \%$ a $66 \%$ dos casos (NICHOLS; YOUNG; SCHILLER, 1987; EVANS, 1983), com alto potencial de morbidade e mortalidade associados. A visualização do segmento é bastante difícil, podendo ser prejudicada pelos ombros, mesmo com técnicas radiográficas específicas, como a incidência do nadador ou tração dos ombros, motivo pelo qual existe uma frequente indicação para realização de exames de imagem mais avançados como a tomografia computadorizada ou a ressonância magnética para melhor estudar esta região da coluna vertebral (WANG; CHOU, 2007). Este mesmo motivo é causa de

O ATLS (Advanced Trauma Life Support), organização fundada em 1978 (KOOL; BLICKMAN, 2007) e hoje ministrada pelo Colégio Americano de Cirurgiões, chegou a recomendar no passado a realização de uma radiografia em perfil da coluna cervical que permitisse visualizar toda a coluna vertebral cervical até o espaço discal entre a sexta e a sétima vértebra cervical, excluindo a transição cervicotorácica na avaliação inicial do trauma. Pela importância das lesões neste segmento, atualmente o ATLS recomenda a realização de uma radiografia da coluna cervical que permita inclusive a visualização da primeira vértebra torácica (KOOL; BLICKMAN, 2007; VANDEN HOEK; PROPP, 1990).

A incidência de lesão neurológica associada com o trauma pode ser elevada, assim como relatado por Sapkas et al. (1999), que em sua série de casos evidenciaram a presença de déficit neurológico em $100 \%$ dos pacientes estudados. Os autores atribuíram este fato ao diâmetro do canal vertebral reduzido e à insuficiência vascular local. Amin e Saifuddin (2005) também demostraram uma alta incidência de déficit neurológico, considerando o padrão de lesão mais comum nesta região a espondilolistese traumática de C7 e T1.

\subsubsection{Tumores}

A incidência de tumores envolvendo o corpo ou pedículos vertebrais na transição cervicotorácica é baixa quando comparada a outras regiões da coluna vertebral, com alguns estudos evidenciando uma prevalência de aproximadamente $15 \%$, sendo que cerca de $10 \%$ das metástases são diagnosticadas acometendo a região de T1 a T4 e as metástases são mais comuns que os tumores primários (SHARAN; PRZYBYLSKI; TARTAGLINO, 2000; LE et al., 2003; NAZZARO; ARBIT; BURT, 1994), O acometimento vertebral na região da transição cervicotorácica por tumores é considerado uma das potenciais causas de instabilidade da região e o déficit neurológico é uma sequela importante atribuída a 
compressões tumorais na região cervicotorácica, podendo chegar a 80\% dos casos (LE et al., 2003).

\subsubsection{Infecções}

Dentre as afecções que acometem a transição cervicotorácica da coluna vertebral, as infecções representam um grupo de patologias que acometem esta região. A tuberculose acomete preferencialmente os ápices pulmonares e não raramente se estendem até a coluna vertebral. Esta invasão e destruição pode levar a instabilidade, deformidade progressiva e consequente compressão das estruturas neurais. Outros agentes infecciosos também são responsáveis pela etiologia da infecção nesta região, com destaque para o S. Aureus (WANG; CHOU, 2007; SAPKAS et al., 1999).

\subsubsection{Outras causas}

A presença de sintomas decorrentes do processo degenerativo é relativamente rara na transição cervicotorácica. A hérnia de disco C7-T1 representa somente 5\% de todas as hérnias de disco cervicais. Nestes pacientes, o sintoma mais comum são os decorrentes do acometimento radicular, e raramente se apresentam como mielopatia (WANG; CHOU, 2007).

A espondilite anquilosante é uma doença auto imune que cursa com a ossificação dos ligamentos causando a anquilose do segmento. A ocorrência de lesões traumáticas da coluna vertebral em pacientes portadores de espondilite anquilosante pode levar a fratura-luxações graves na transição cervicotorácica (MA et al., 2015).

A espondilite anquilosante pode gerar deformidades graves na região cervicotorácica, sendo uma das mais graves a deformidade conhecida com "queixo no peito". Esta ocorre quando o paciente apresenta um aumento da cifose na transição cervicotorácica e o queixo entra em contato com o peito do paciente, em uma posição rígida, necessitando de tratamento cirúrgico para sua correção (WANG; CHOU, 2007).

As malformações congênitas associadas ou não à alguma síndrome genética também podem afetar a transição cervicotorácica. Este grupo de patologias costuma cursar com deformidades precoces podendo inclusive necessitar de abordagem cirúrgica neste segmento. Uma deformidade não tratada pode evoluir simultaneamente com sequelas em outros segmentos como deformidades em face, mandíbula, malformação ocular, disfonia, dentre outros (MULPURI et al., 2005). 


\subsubsection{Biomecânica da coluna vertebral}

As características biomecânicas da coluna vertebral são um assunto importante de abordar quando se estuda o tratamento das afeções que acometem a coluna vertebral.

Conforme descrito por Pal e Routal, 1986, desde a década de 40 diversos estudos e livros textos já descreviam a transmissão de cargas pelos corpos vertebrais e discos

Com o envelhecimento existe aumento progressivo da cifose torácica assim como descrito por Fon, Pitt e Thies (1980) o que também parece sobrecarregar as facetas da transição cervicotorácica, além de ocorrer a transferência da transmissão de cargas da região anterior da coluna para a região posterior, tornando assim a transição mais susceptível a lesões (PAL; ROUTAL, 1986; BOYLE; SINGER; MILNE, 1996). A biomecânica desta região de transição depende dentre muitos fatores da relação entre a cifose torácica e da lordose lombar. Sabe-se que esta relação muda conforme a idade em indivíduos de ambos os sexos com o aumento desta angulação mais notado após os 40 anos e tendo como possível causa às alterações da densidade mineral óssea e de partes moles (FON; PITT; THIES, 1980).

Boyle, Singer e Milne (1996) e Panjabi et al. (1991) descreveram um índice que relaciona a área da placa vertebral superior com a altura da cortical posterior, chamando este índice de índice vertebral, com o objetivo de melhor estudar a transição cervicotorácica. Os autores relacionam a diferença do índice vertebral descrito com uma maior sobrecarga em uma vértebra menor e com menor área de superfície, uma vez que em T1 este índice é menor que comparado com C6 e C7. Os mesmos autores defendem que isto poderia ser relacionado para explicar uma maior incidência de artrose facetária entre C7 e T1.

\subsubsection{Abordagem cirúrgica para a transição cervicotorácica}

A coluna vertebral pode ser acessada basicamente de duas formas: pelas abordagens anterior ou posterior. Na região da transição cervicotorácica da coluna vertebral a maioria das lesões estão localizadas na região do corpo vertebral, fato que torna a abordagem anterior um acesso bastante utilizado para o tratamento destas patologias (POINTILLART et al., 2007). O acesso anterior para a transição cervicotorácica da coluna vertebral representa um desafio para o cirurgião em decorrência da presença de importantes estruturas anatômicas como o esterno, a clavícula e os grandes vasos (POINTILLART et al., 2007).

\subsection{Abordagens anteriores}

As principais técnicas cirúrgicas descritas utilizadas para o acesso anterior à transição cervicotorácica são: acesso anterolateral cervical (SMITH; ROBINSON; PERRY); supra 
clavicular; transtorácico; transaxilar, esternotomia (CAUCHOIX) e suas variantes (NAZZARO et al., 1994) e esternocleidotomia (SAPKAS et al., 1999).

Todas as abordagens tem o potencial de oferecer uma exposição e área de trabalho ideal, variando bastante na agressividade do acesso cirúrgico e consequentemente na morbidade e mortalidade relacionados aos procedimentos. Os acessos na transição cervicotorácica são limitados pela profundidade do corpo vertebral como resultado da cifose torácica, e a presença de diversas estruturas importantes na região (WANG; CHO, 2007).

A abordagem de escolha depende da anatomia do paciente, patologia e sua extensão, habilidade e familiaridade com as técnicas pelo cirurgião e programação cirúrgica (BEUTLER; SWEENEY; CONNOLLY, 2001).

\subsection{Acesso Anterolateral}

O acesso anterolateral foi primeiramente descrito por Smith e Robinson (KNOLLER; BRETHNER, 2002) e melhor detalhado para a região mais distal da coluna cervical por Perry (1977) (BIRCH; BONNEY; MARSHALL, 1990), utiliza o espaço anterior à bainha carotídea até a coluna vertebral (WANG; CHOU, 2007).

Durante o acesso anterolateral, passos técnicos como evitar a hiperextensão da cabeça para não causar a redução do canal vertebral e aumentar a tensão dos vasos supra-aórticos, evitar a dissecção agressiva do subcutâneo do platisma devido à vascularização do mesmo advinda desta são detalhes que podem reduzir as taxas de complicação (WANG; CHOU, 2007).

O nervo laríngeo recorrente, ramo do nervo vago, é uma das principais estruturas em risco neste acesso, com taxas de lesão que variam de 0,07 a 11\% (BEUTLER; SWEENEY; CONNOLLY, 2001). Alguns autores defendem a desinsuflação do balão do tubo traqueal antes do afastamento como medida para reduzir a taxa de lesões ao nervo por tração excessiva da traqueia (SIMON et al., 2004).

Historicamente, alguns autores chegaram a defender a abordagem pelo lado esquerdo devido à anomalias anatômicas do nervo do lado direito, reduzindo o risco de lesão por este lado. Existem evidências, no entanto de que nem a realização do acesso pelo lado esquerdo é mais segura, nem a presença de anomalias do lado direito são relevantes, e que a lesão do nervo recorrente estaria mais relacionada à tração excessiva das estruturas envolvidas (GIEGER; ROTH; WU, 1995; BEUTLER; SWEENEY; CONNOLLY, 2001; HALLER; IWANIK; SHEN, 2011). 
O gânglio torácico é outra estrutura em risco nesta abordagem que encontra-se em uma posição anterolateral ao disco de C7 a T1. O duto torácico é outra estrutura que apresenta risco durante o acesso cirúrgico, quando se opera do lado esquerdo.

O duto torácico pode ascender até o nível de C6, apesar de normalmente ser encontrado em níveis de C7 a T1.

O duto está localizado no meio do triângulo formado medialmente pelo músculo longo do pescoço e esôfago, lateralmente pelo músculo escaleno anterior e inferiormente pela primeira costela (GIEGER; ROTH; WU, 1995). Normalmente este apresenta uma grande variação anatômica quanto ao local de drenagem, sendo mais comum a junção da veia subclávia esquerda com a veia jugular interna esquerda (SIMON et al., 2004).

\subsection{Esternotomia / Manubriotomia}

A esternotomia total ou parcial para a visualização da região da transição cervicotorácica foi primeiramente descrita por Cauchoix em 1957, foi posteriormente modificada por Louis em 1982 para combiná-la com a via de Smith-Robinson em um único acesso e permitir a visualização da transição até a região de $\mathrm{C} 2$, oferecendo uma ampla visualização da transição cervicotorácica. Quando comparado com o acesso cervical anterior de Smith-Robinson e, dependendo da anatomia da coluna torácica proximal, torna-se difícil a exposição e a área de trabalho da vértebra distal. A esternotomia em relação aos outros acessos da região torácica alta, como o descrito por Kurz ou o por Hodigson e Stock, oferece como vantagem a não interferência da função do ombro e como desvantagem uma maior profundidade da ferida e a estreita área de trabalho (KNOLLER; BRETHNER, 2002).

$\mathrm{Na}$ realização do acesso algumas medidas como a rotação da cabeça, coxim entre as escápulas, sonda nasogástrica, borda de segurança de $2 \mathrm{~cm}$ na incisão do músculo esternocleidomastóideo para facilitar sua reinserção, cuidados na hora de se realizar a osteotomia da cortical posterior do esterno, ressecção do ligamento interescapular e atenção na osteotomia da cortical posterior do esterno podem reduzir as complicações no intra e pós operatório. A extensão da esternotomia, a opção por manúbriotomia e outras variações da esternotomia também foram descritas para reduzir a agressão e consequentemente a morbidade do procedimento (XIAO; GONG; LEE, 2007). As estruturas retroesternais podem ser afastadas para caudal e anterior. Desta forma não é necessária a dissecção de grandes vasos. Este acesso normalmente é limitado pelo arco da aorta, nos níveis de T4-T5. Em alguns casos, para se atingir níveis mais distais, também é necessária a ligadura da veia braquiocefálica esquerda (KNOLLER; BRETHNER, 2002). 
Algumas variações desta abordagem foram descritas e também podem ser aplicadas. Xiao, Gong e Lee (2007) sugeriram que a abordagem fosse realizada em um espaço encontrado entre a veia braquiocefálica direita e a artéria braquiocefálica (XIAO; GONG; LEE, 2007), e Le Huec et al., os quais descreveram a técnica assistida por videoscopia para a realização de uma cirurgia menos invasiva, seguindo uma tendência de se buscar uma abordagem menos agressiva durante o procedimento (LE HUEC et al., 2001).

Quanto existe a necessidade do acesso ser caudal à níveis alcançados pela esternotomia, o que normalmente ocorre próximo de T4, a toracotomia é uma opção. Entretanto, a toracotomia não permite a extensão do acesso para a região cervical baixa. Nestes casos, a técnica “Trap-door” descrita por Nazzaro et al. (1994) pode ser usada como uma alternativa.

\subsection{Esternocleidotomia}

A esternocleidotomia foi descrita por Sundaresan et al. (1984) como alternativa à esternotomia, por este acesso é maior a facilidade de colocação e enxerto ósseo, quando comparado às outras técnicas cirúrgicas, devido ao canal de trabalho mais amplo e uma menor limitação por parte do esterno. O acesso é realizado ressecando-se uma porção do manúbrio e o 1/3 distal da clavícula, adentrando no espaço entre a traqueia e o esôfago medialmente e a bainha carotídea lateralmente (CHARLES; GOVENDER, 1989; BIRCH; BONNEY; MARSHALL, 1990).

\subsection{Programação cirúrgica}

A grande preocupação que existe nas vias de acesso que demandam a realização de osteotomias é o aumento das taxas de complicações e morbidades relacionadas com o procedimento cirúrgico (KARIKARI; POWERS; ISAACS, 2009; BOYLE; SINGER; MILNE, 1996).

A necessidade ou não de uma via que envolva a osteotomia da clavícula ou do esterno depende das relações da coluna com o esterno. Alguns autores buscaram através do desenvolvimento de diferentes métodos prever a viabilidade de uma abordagem na transição cervicotorácica por análise de radiografias, tomografias computadorizadas ou ressonância magnética sem a necessidade de osteotomias (FALAVIGNA; RIGHESSO; TELES, 2009). 


\subsubsection{Métodos de programação pré-operatória}

Os primeiros estudos que investigaram métodos para prever a necessidade ou não de uma esternotomia são atribuídos a Sharan, Przybylski e Tartaglino, no ano de 2000. Os autores determinaram uma linha que tangencia a incisura supraesternal e a linha discal, identificada pelo disco intervertebral mais distal cruzando acima do esterno.

O estudo dos autores Sharan, Przybylski e Tartaglino de 2000 envolveu a seleção de 106 pacientes e suas imagens de ressonância magnética foram submetidas às análises. Segundo os autores, a linha horizontal é o último nível caudal o qual se pode acessar a coluna sem a necessidade de se adentrar pelo desfiladeiro torácico, e a linha discal seria somente o último disco possível de ser visualizado por completo acima do esterno. Os autores defendem não ser necessária a utilização de osteotomias no manúbrio e/ou esterno quando ambas as linhas encontram-se distais à patologia.

Em 2002, Fraser et al. compararam diversos parâmetros para auxiliar o cirurgião na escolha da via de acesso das patologias da transição cervicotorácica. Em 2007, Lakshmanan et al. analisando 102 exames de ressonância magnética, de dois hospitais do Reino unido, descreveram um método semelhante ao descrito por Sharan, Przybylski e Tartaglino, no qual uma linha era traçada tangente ao manúbrio com o objetivo de determinar o nível passível de ser operado sem a necessidade de uma osteotomia no esterno. Por outro lado, baseado na análise de exames de tomografia computadorizada, Karikari, Powers e Isaacs, defenderam em 2009 que somente a linha discal seria suficiente para predizer a necessidade ou não de um procedimento no esterno. Os autores estudaram 50 casos para avaliar a distribuição dos níveis discais e testaram o método em 12 pacientes (KARIKARI; POWERS; ISAACS, 2009).

Teng et al. (2009) propuseram o ângulo cervicotorácico como método de programação pré-operatória. O ângulo é formado por duas linhas ambas com origem na incisura supraesternal, nos cortes sagitais na linha média. Uma das linhas é traçada na direção horizontal até tocar a coluna vertebral, e a segunda linha é traçada até o nível discal C7-T1. Os autores consideram que lesões localizadas acima deste ângulo não necessitam de abordagens que envolvam osteotomias no esterno, lesões entre esse ângulo podem não necessitar de osteotomias no esterno e lesões abaixo do ângulo, vão necessitar de abordagens que incluam osteotomias no esterno. Em 2011 Falavigna, Righesso e Teles propuseram algumas alterações no método proposto por Sharan, Przybylski e Tartaglino (2000). Os autores incluíram a avaliação pré-operatória por meio de exame de ressonância magnética para a avaliação de anomalias vasculares que contra indicassem o procedimento cirúrgico, por 
meio da utilização de uma linha da vertebral mais cranial para avaliar a necessidade de se realizar ou não uma esternotomia.

Choi et al. (2011) propuseram que nos casos em que fosse possível a realização da via anterolateral após estudos de imagens, deveria haver uma mudança na técnica cirúrgica, propondo a abordagem de foraminotomia cervical anterior ou suas modificações.

Em 2016, Mai et al. utilizaram o método descrito por Sharan, Przybylski e Tartaglino (2000), que envolvia a determinação do nível discal mais distal (ND), em exames de ressonância magnética. Além deste parâmetro, outros como índice de massa corpórea (IMC), altura, peso, sexo e idade também foram avaliados. Os autores concluíram que o nível discal cervical com maior correlação da linha discal é o nível de T1 e T2, que a altura do indivíduo não influencia neste parâmetro, uma vez que o fêmur e a tíbia são os maiores responsável pelo tamanho do paciente e que a obesidade é um fator de risco para alterações no ND (MAI et al., 2016). 
OBJETIVOS 


\section{OBJETIVOS}

\subsection{Objetivo geral}

Avaliar os parâmetros de programação pré-operatórios selecionados para a transição cervicotorácica em uma amostra da população brasileira, por meio estudo de imagens de tomografia computadorizada.

\subsection{Objetivos específicos}

- Comparar o nível discal de uma amostra da população brasileira com outras populações já estudadas;

- Comparar o nível horizontal em relação ao esterno de uma amostra da população brasileira com outras populações já estudadas;

- Avaliar possíveis diferenças entre o nível discal de uma amostra da população brasileira quanto a idade e sexo;

- Avaliar as diferenças entre o nível horizontal em relação ao esterno de uma amostra da população brasileira quanto a idade e sexo;

- Avaliar diferenças da angulação do nível discal de uma amostra da população brasileira e sua relação com a idade e sexo;

- Avaliar diferenças da angulação do corpo relacionado ao nível horizontal em relação ao esterno de uma amostra da população brasileira e sua relação com a idade e o sexo. 
MATERIAIS E MÉTODO 


\section{MATERIAIS E MÉTODO}

\subsection{Desenho da Pesquisa}

Este é um estudo transversal, retrospectivo, observacional e realizado em um centro único. O estudo foi aprovado pelo Comitê de Ética e Pesquisa do Hospital das Clínicas da Faculdade de Medicina de Ribeirão Preto - USP (Anexos). O estudo foi isento da aquisição do Termo de Consentimento Livre e Esclarecido, por se tratar de uma revisão de exames realizados por outros motivos, fazendo parte do arquivo radiológico da divisão de Radiologia do Hospital das Clínicas de Ribeirão Preto da Faculdade de Medicina de Ribeirão Preto.

\subsection{Revisão de literatura}

Para este estudo, uma revisão da literatura acerca dos métodos de programação préoperatório para abordagens anteriores na coluna na região cervicotorácica foi realizada. Procuramos por trabalhos científicos, de qualquer data que envolvessem tanto exames de Ressonância Magnética, quanto Tomografias computadorizadas e contemplassem os termos "cervicothoracic junction", "transição cervicotorácica", "cervicothoracic spine", "coluna cervicotorácica" e "cervicothoracic column", nos bancos de dados da Pubmed, Google Science, Cochrane, clinicaltrials.org e ensaiosclinicos.gov.br, em data prévia à abril de 2015 . Não existem trabalhos até o presente momento que relacionem em conjunto tais parâmetros radiográficos com idade e sexo em grupos diferentes ou mesmo comparando diferentes populações.

\subsection{Amostra}

Foram selecionados 300 estudos de tomografia computadorizada do banco de dados da divisão de Radiologia do Hospital das Clínicas de Ribeirão Preto, realizados no período de 2008 a 2014.

\subsection{Critérios de inclusão}

Foram incluídos neste trabalho os exames de tomografia computadorizada de tórax ou coluna torácica que apresentavam resultado do laudo normal ou dentro da normalidade, ou 
seja, casos em que existam alterações degenerativas compatíveis com a idade, pacientes acima de 18 anos, realizados na divisão de Radiologia do Hospital das Clínicas de Ribeirão Preto FMRP - USP.

\subsection{Critérios de exclusão}

Foram excluídos da avaliação exames tomográficos de pacientes com o diagnóstico radiológico de patologias da coluna vertebral como tumor, infecção, fraturas da coluna ou cirurgia prévia. Além disso, foram excluídos os exames nos quais não fosse possível identificar as estruturas estudadas: esterno e transição cervicotorácica da coluna vertebral.

\subsection{Obtenção das imagens}

Os exames de tomografia computadorizada utilizadas neste estudo foram realizados em um aparelho Phillips "Multislice" de 64 canais, modelo "Brilliance Big Bore", com cortes de $2 \mathrm{~mm}$ de espessura.

\subsection{Avaliação das imagens}

Todos os exames de tomografia computadorizadas foram avaliados por um mesmo pesquisador (R.L.S.), no mesmo programa de computador. Os arquivos radiográficos são do formato DICOM e foram analisados por meio do programa OsiriX MD, FDA-Cleared / CE IIa (Pixmeo SARL), que permite a reconstrução 3D das imagens tomográficas e de aferição das medidas.

Em todos os casos, as imagens tomográficas eram reconstruídas nos cortes sagital, coronal e transversal. O plano escolhido para a realização das medidas foi o sagital na linha média (Figura 7). Para cada mensuração obtida, o avaliador certificava-se do alinhamento correto e centrado nos três planos apresentados simultaneamente, realizando correções quando necessário. 


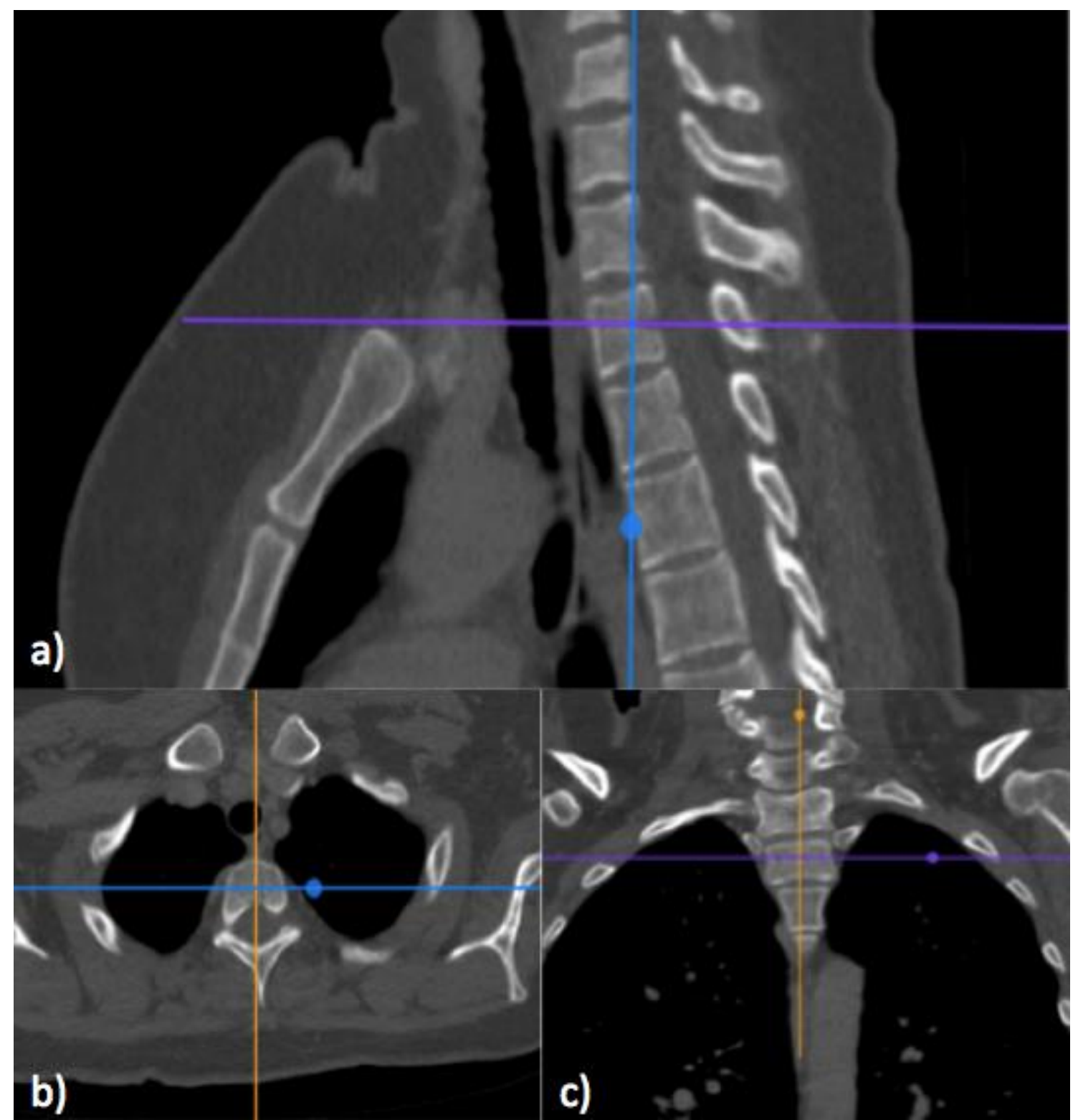

Figura 7 - Reconstrução 3D de exame de tomografia da coluna torácica com o alinhamento da reconstrução nos planos a) sagital, b) transversal e c) frontal.

Fonte: Arquivo pessoal.

\subsection{Parâmetros estudados}

\subsubsection{Variáveis clínicas}

As variáveis clínicas estudadas para cada caso foram a idade e o sexo dos pacientes. 
Foram criados dois grupos principais para o estudo: sexo masculino e sexo feminino. Estes dois grandes grupos foram subdivididos em três outros de acordo com a faixa etária: de 18 a 40 anos, 41 a 60 anos e acima de 60 anos, cada um contendo uma amostra de 50 exames de imagem, totalizando 300exames e 6 subgrupos.

\subsubsection{Variáveis radiológicas}

Os parâmetros estudados foram: (1) nível horizontal em relação ao esterno, (2) angulação do corpo, (3) nível discal e (4) angulação do nível discal. A lista de terminologia de todos os parâmetros que foram mensurados com suas respectivas abreviações e descrições estão resumidas na Tabela 1.

Tabela 1 - Parâmetros mensurados nas imagens sagitais de tomografia computadorizada.

\begin{tabular}{lcc}
\hline \multicolumn{1}{c}{ MEDIDA } & SIGLA & DESCRIÇÃo \\
\hline Nível Discal & ND & Linha discal mais distal que cruza acima do \\
$\begin{array}{l}\text { Nível Horizontal em } \\
\text { Relação ao Esterno }\end{array}$ & NHE & $\begin{array}{c}\text { Porção vertebral interseccionada por uma } \\
\text { linha perpendicular em relação ao manúbrio } \\
\text { Angulação do Corpo }\end{array}$ \\
$\begin{array}{l}\text { Angulação do Nível } \\
\text { Discal }\end{array}$ & AC & $\begin{array}{c}\text { Angulação do corpo intersecionado pela NHE } \\
\text { em relação à mesma }\end{array}$ \\
\hline
\end{tabular}

Fonte: $\mathrm{O}$ autor.

(1) Nível horizontal em relação ao esterno (NHE)

O nível horizontal em relação ao esterno (NHE é uma medida perpendicular ao plano sagital do paciente, que tangencia a incisura do manúbrio do esterno e cruza a coluna vertebral (Figura 8), obtida na reconstrução sagital da tomografia computadorizada. O primeiro passo consiste na centralização das imagens em todos os planos. Após, uma linha perpendicular ao plano sagital do paciente foi traçada à partir do ponto central da incisura do esterno. No ponto que esta linha cruzava a coluna vertebral, a vértebra interceptada foi considerada o nível determinado por este parâmetro. No caso deste nível corresponder à um espaço discal, a vértebra imediatamente superior foi eleita como o parâmetro estudado: NHE. 


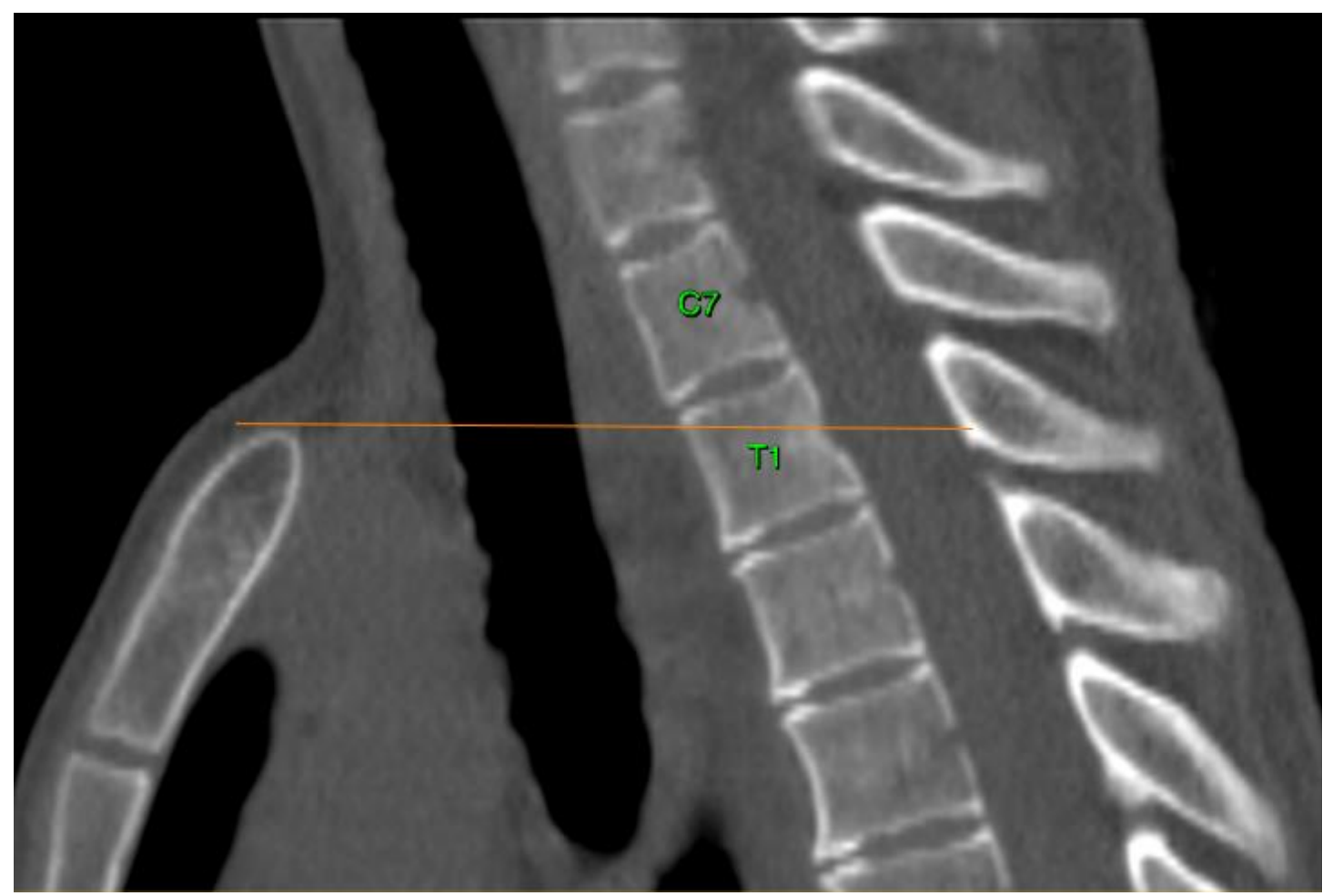

Figura 8- Imagem sagital de tomografia computadorizada ilustrando o método de identificação do nível horizontal em relação ao esterno (NHE)

Fonte: Arquivo pessoal

\subsubsection{Angulação do corpo vertebral (AC)}

A angulação do corpo vertebral consistiu na mensuração em graus da inclinação da cortical anterior do corpo seccionado pelo parâmetro NHE em relação ao plano sagital do paciente (Figura 9). Para a mensuração deste parâmetro, primeiro foi identificado o corpo correspondente ao NHE. Após identificado o corpo, uma linha foi traçada na cortical anterior da vértebra e o ângulo obtido entre essas linhas foi considerado o AC. 


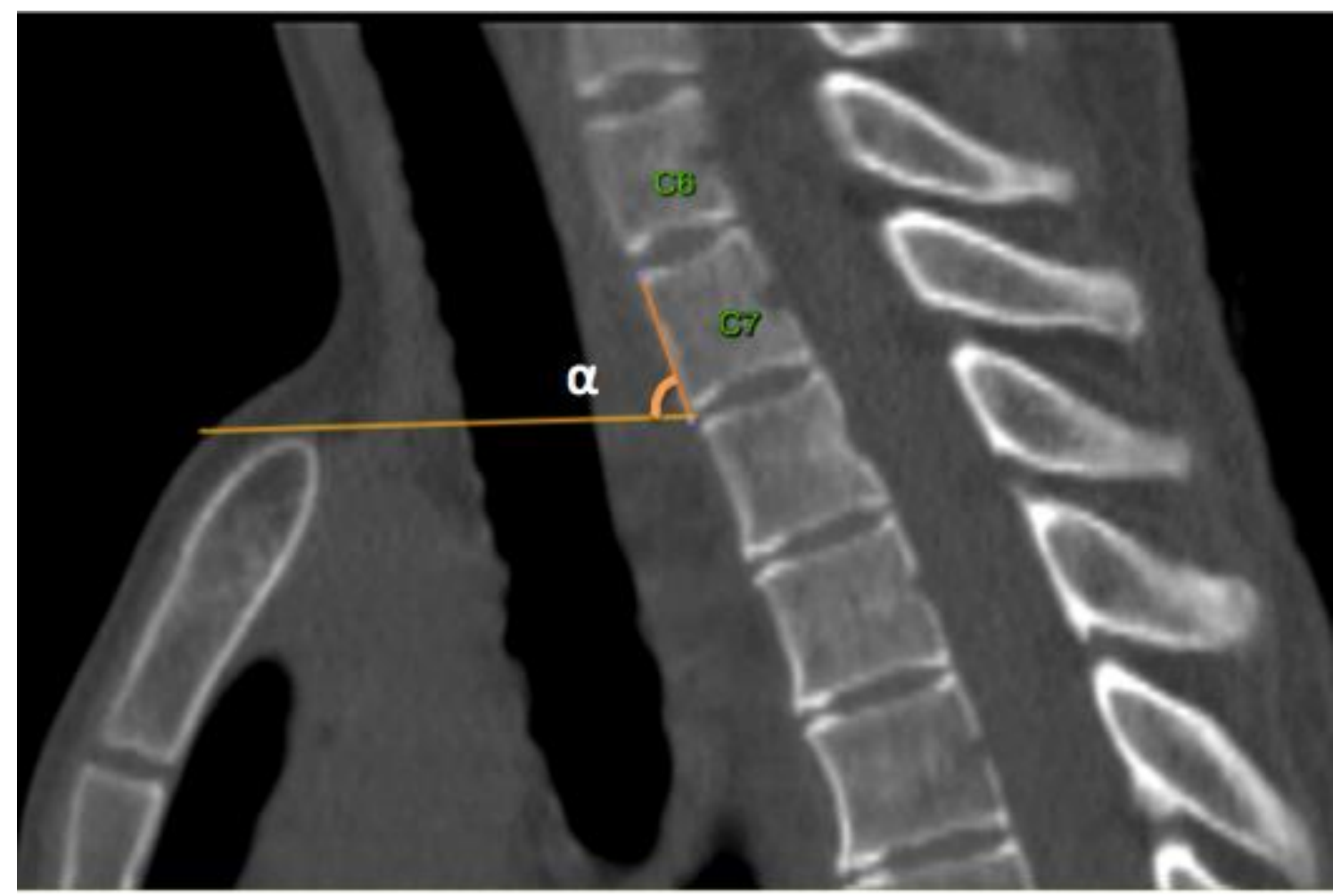

Figura 9 - Imagem sagital de tomografia computadorizada ilustrando a técnica de obtenção da angulação do corpo (AC), representado por $\alpha$.

Fonte: Arquivo pessoal

\subsubsection{Nível discal (ND)}

O nível discal correspondeu a uma linha traçada à partir do espaço discal, sendo o nível determinado para representar este parâmetro o último disco intervertebral que passa acima da incisura do corpo do esterno (Figura 10). Em um primeiro momento foram traçadas linhas cruzando o centro dos discos intervertebrais. O disco intervertebral mais distal cuja linha incidisse acima da incisura do esterno era considerado o ND. 


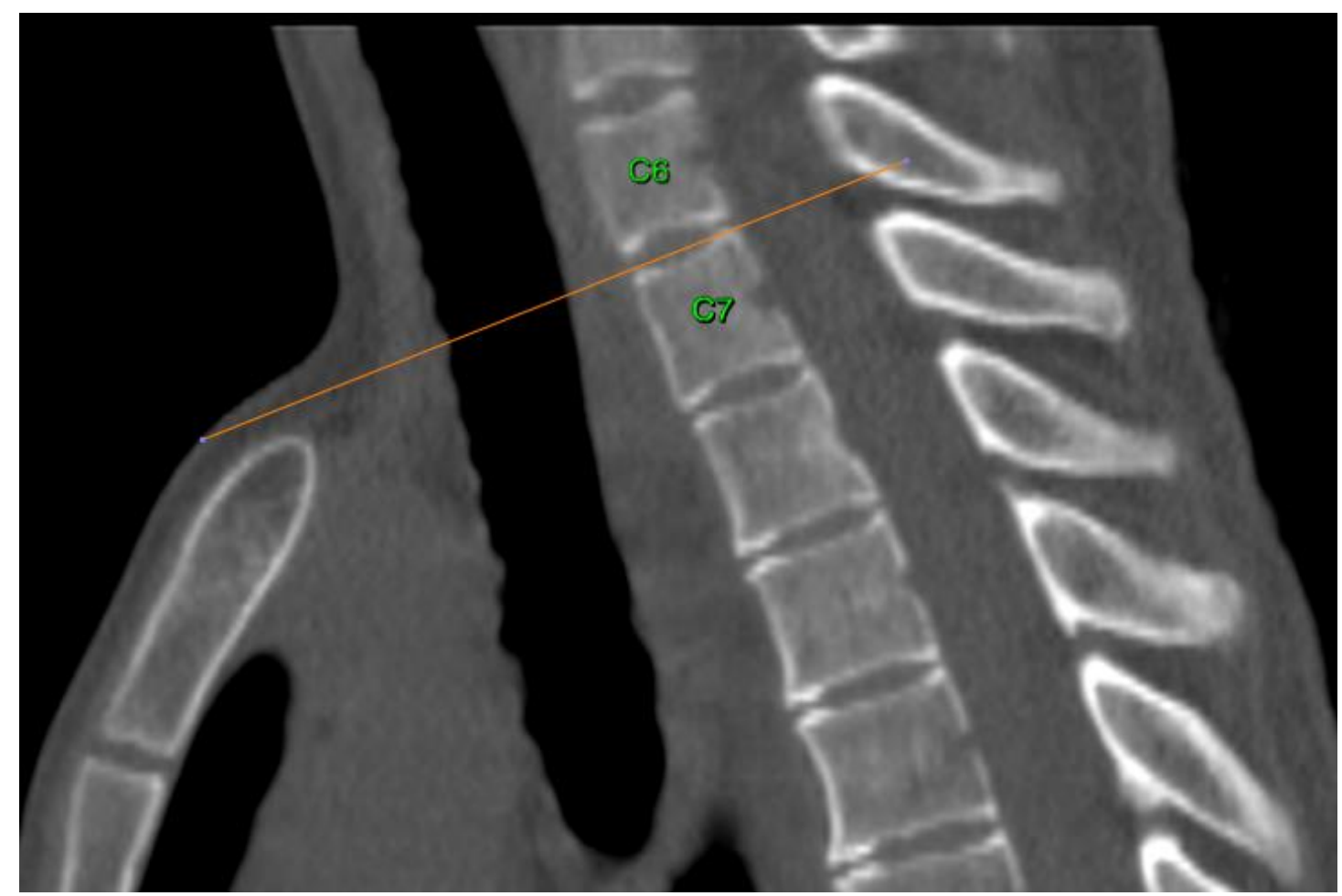

Figura 10 - Imagem sagital de tomografia computadorizada ilustrando o método de identificação do nível discal (ND)

Fonte: Arquivo pessoal

\subsubsection{Angulação do nível discal (AND)}

A angulação do nível discal (AND) representa a angulação do ND em relação ao plano transversal do paciente, também correspondendo ao NHE (Figura 11). A obtenção deste parâmetro foi realizada com a obtenção do ângulo entre AND e NHE, coincidentemente representado pela mesma linha do plano transversal do paciente. 


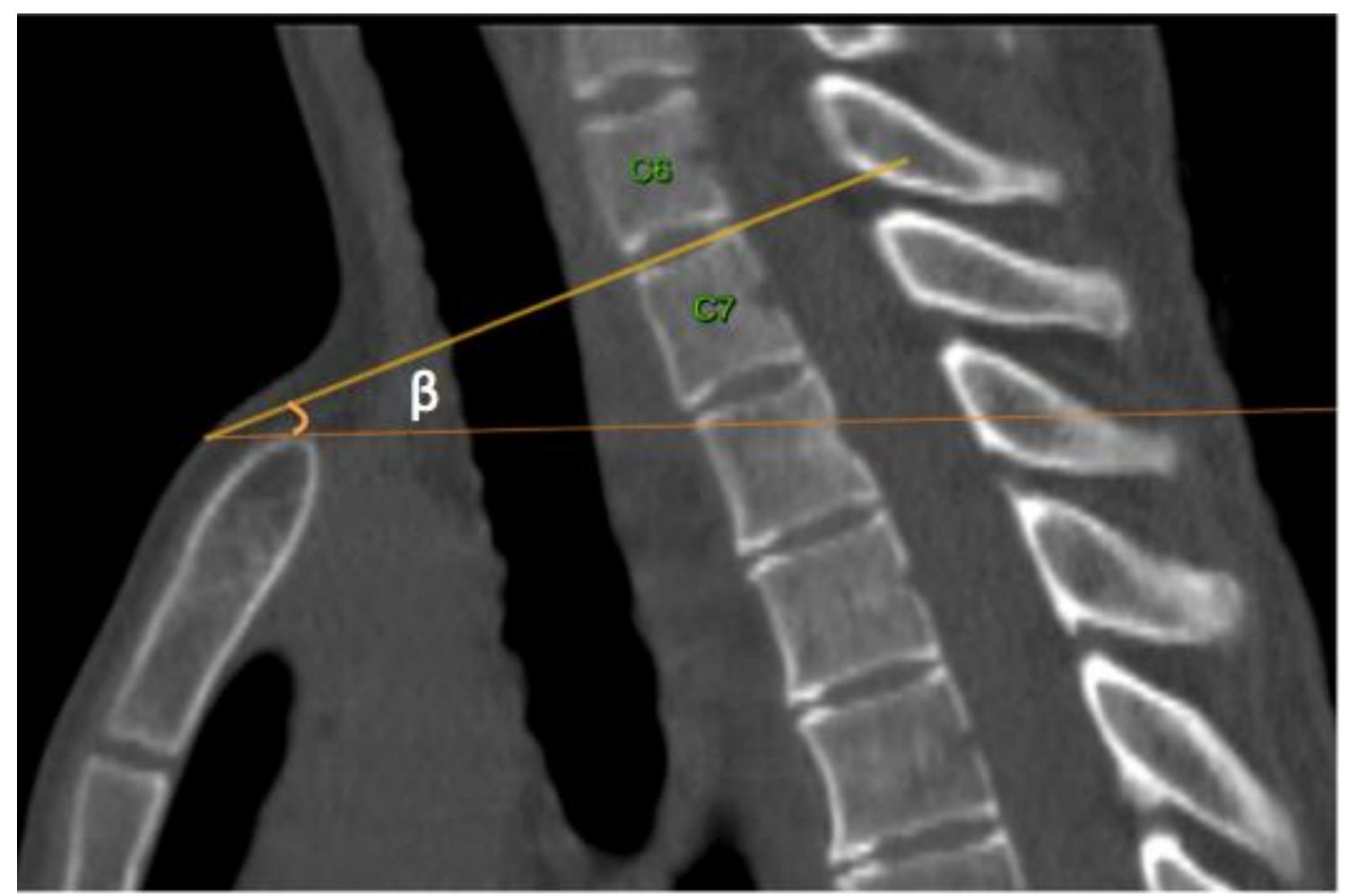

Figura 11 - Imagem sagital de tomografia computadorizada ilustrando o método de identificação do angulação do nível discal (AND), representado por $\beta$.

Fonte: Arquivo pessoal

\subsubsection{Análise estatística}

As variáveis paramétricas (AND e AC) foram apresentadas em média e desvio padrão, enquanto as variáveis não paramétricas (ND e NHE) apresentadas em porcentagens. A análise estatística envolveu a comparação de todos os parâmetros estudados (NHE, AC, ND e AND) entre os grupos, com relação ao sexo e a faixa etária. Assim, o primeiro passo foi transformar as variáveis categóricas SEXO e IDADE em variáveis ordinais.

As variáveis paramétricas (AND e AC) foram submetidas aos testes para análise de possível distribuição normal pelo teste Shapiro-Wilke, formato do histograma e comparação da média com a mediana. Posteriormente foi utilizado os testes t de Student e ANOVA-TWO WAY para compará-las estatisticamente de acordo com os grupos sexo e faixa etária, respectivamente. Após isso foi realizado o pós teste de Bonferroni.

As variáveis não paramétricas estudadas (ND e NHE) foram convertidas em variáveis ordinais numéricas (Tabelas 2 e 3), para a análise estatística. O nível de C5-6 foi o ND mais proximal encontrado nesta amostra, logo foi considerado como o primeiro parâmetro desta variável ordinal. O nível de C7 foi considerado como sendo o primeiro nível, pois nos dados 
coletados este corresponde ao NHE mais proximal encontrado. A análise estatística da variável NHE e ND foi realizada por meio do teste de Pearson Chi-quadrado.

Todos os parâmetros foram analisados pelo programa STATA13 ${ }^{\circledR}$ (StataCorp. 2013. Stata Statistical Software: Release 13. College Station, TX: StataCorp LP), e o valor de p considerado foi de 0.05 .

Tabela 2 - Conversão do parâmetro nível discal (ND) em variável ordinal

\begin{tabular}{cc}
\hline \multicolumn{2}{c}{ Nível discal (ND) } \\
\hline C5-6 & 1 \\
C6-7 & 2 \\
C7-T1 & 3 \\
T1-2 & 4 \\
T2-3 & 5 \\
T3-4 & 6 \\
\hline Fonte: O autor.
\end{tabular}

Tabela 3 - Conversão da variável NHE em variável ordinal

\begin{tabular}{cc}
\hline \multicolumn{2}{c}{ NíVEL HORIZONTAL } \\
\hline C7 & 1 \\
DISCO C7-T1 & 2 \\
T1 & 3 \\
DISCO T1-2 & 4 \\
T2 & 5 \\
DISCO T2-3 & 6 \\
T3 & 7 \\
DISCO T3-4 & 8 \\
T4 & 9 \\
\hline Fonte: O autor
\end{tabular}


RESULTADOS 


\section{RESULTADOS}

Embora a relação do esterno com a coluna vertebral tenha sido demonstrada previamente na literatura, não existem estudos prévios em uma mostra significante da população brasileira ou estudos que correlacionem os achados com o sexo e a idade dos indivíduos (SHARAN; PRZYBYLSKI; TARTAGLINO, 2000; FRASER et al., 2002; KARIKARI; POWERS; ISAACS, 2009).

Com relação às características clínicas, o grupo de indivíduos do sexo masculino apresentou a idade variando de 18 a 91 anos, com uma média de 49 anos e desvio padrão de 18 anos. Já o grupo de indivíduos do sexo feminino apresentou a idade variando de 18 a 91 anos, porém com uma média de idade de 51 anos e o desvio padrão de 20 anos. A média de idade geral foi de 50 anos, com o desvio padrão de 23 anos (Tabela 4).

Tabela 4 - Distribuição das idades e respectivos desvios padrão

\begin{tabular}{lccc}
\hline & Homens & Geral & Mulheres \\
\hline Média & 49 & 50 & 51 \\
Desvio padrão & 18 & 23 & 20 \\
\hline
\end{tabular}

Fonte: $\mathrm{O}$ autor.

O nível horizontal em relação ao esterno (NHE) variou de C7 a T4, sendo que o nível mais frequente foi o nível T2 em 34,3\% dos casos analisados, seguido pelo disco intervertebral T1-T2 e o disco intervertebral T2-T3 com 20,7\% e 17,3\%, respectivamente. Os NHE menos frequentes foram T4 e C7, encontrados em, respectivamente, $0,3 \%$ e $1 \%$ dos exames avaliados (Gráfico 1). 


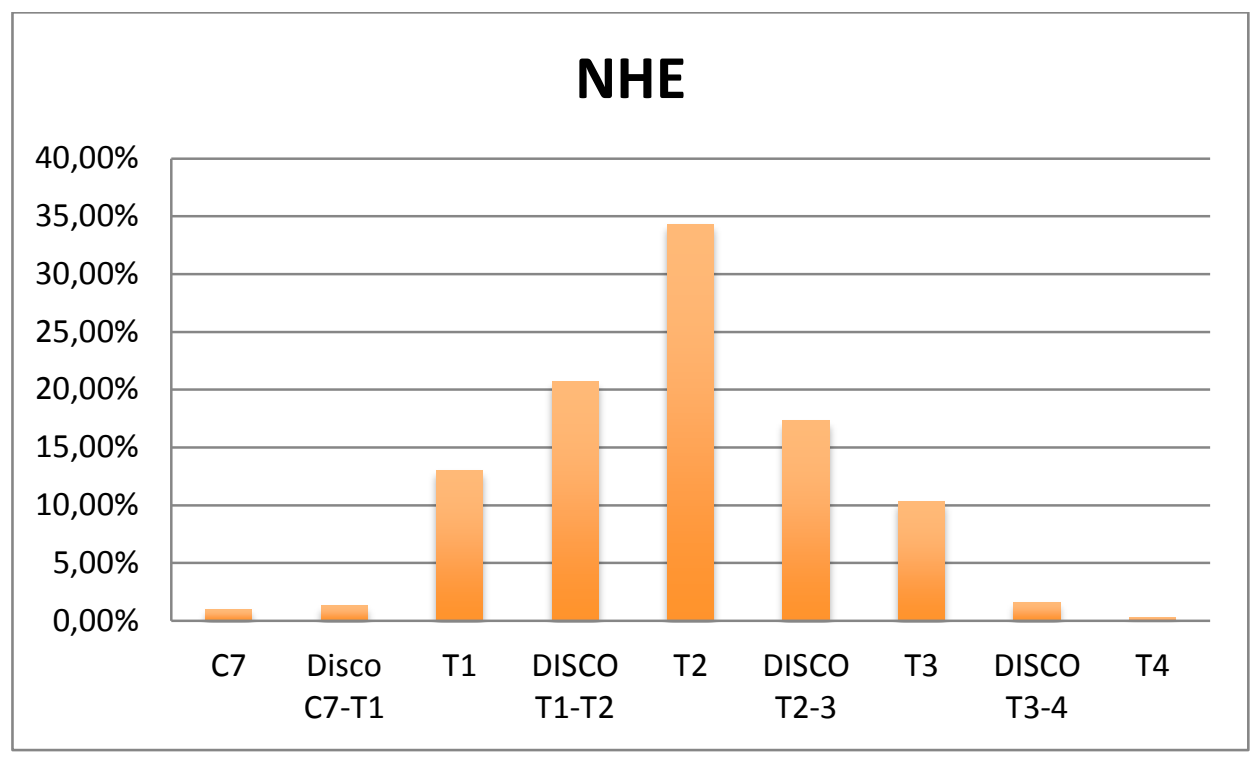

Gráfico 1 - Distribuição dos resultados de NHE (por nível) em porcentagem. Fonte: $\mathrm{O}$ autor.

A avaliação da angulação do corpo vertebral (AC) e da angulação do nível discal (AND) em nossa amostra evidenciou uma média de 18,51 graus ( $\pm 8,94$ graus) e 19,63 graus ( $\pm 7,90$ graus), respectivamente $\mathrm{O}$ AC variou de 1,29 graus a 54,32 graus, enquanto o AND variou de 0 grau a 49 graus.

O nível discal (ND) na amostra estudada variou de C5-C6 a T2-T3, sendo C7-T1 o ND mais frequente, representando $46 \%$ dos exames avaliados. Em seguida os NDs mais encontrados foram T1-T2 e C6-C7, com 26,7\% e 22,3\% respectivamente. Os NDs menos frequente foram T2-T3 3 C5-C6, responsáveis por 1,7\% e 3\% dos achados. (Gráfico 2)

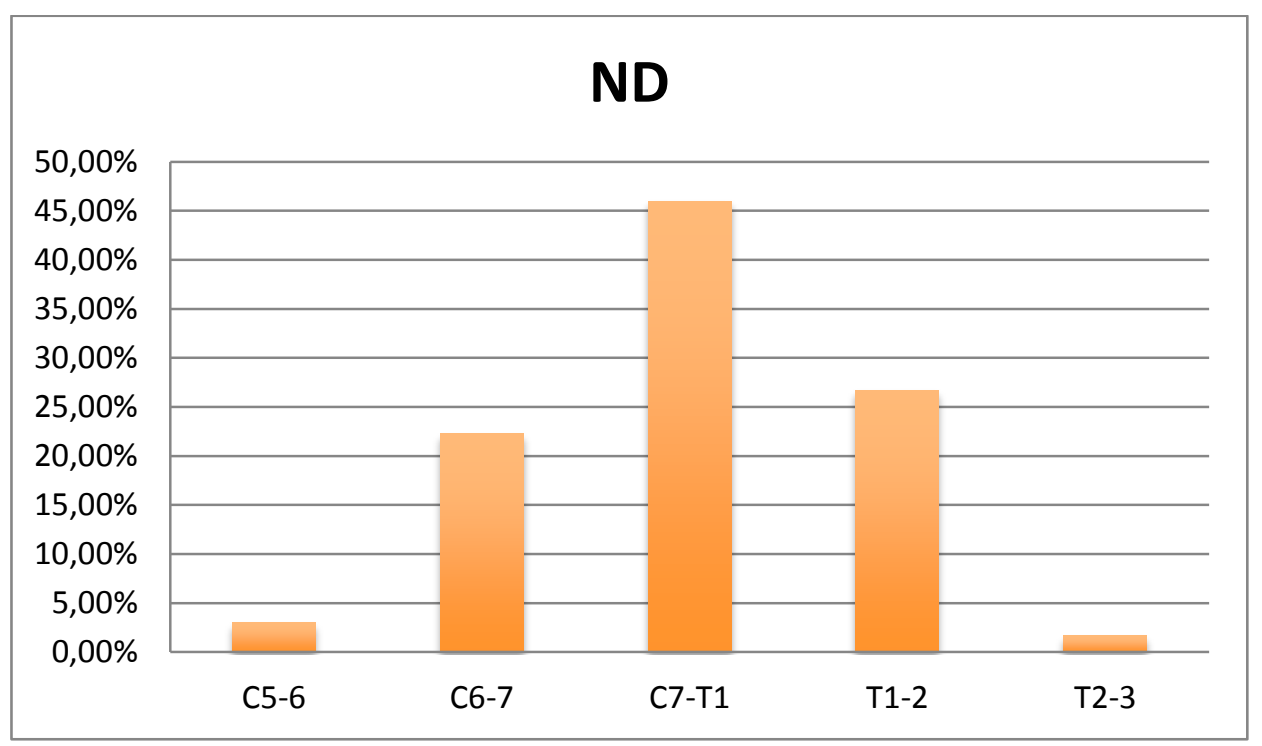

Gráfico 2 - distribuição dos resultados de NHE (por nível) em porcentagem. Fonte: $\mathrm{O}$ autor. 
Comparado o AND entre o grupo de indivíduos do sexo masculino com o grupo de indivíduos do sexo feminino, houve diferença estatisticamente significante $(p=0,003)$, sendo o valor encontrado maior no grupo do sexo masculino (Tabela 5).

Houve diferença estatisticamente significante quando comparado os valores da AND entre os grupos etários ( $\mathrm{p}=0,01)$. Após a aplicação do pós teste de Bonferroni, observou-se uma diferença estatisticamente significante entre os grupos 1 e 2 ( $\mathrm{p}=0,001)$, estatisticamente significante entre os grupos 2 e $3(\mathrm{p}=0,01)$ e muito significante entre os grupos 1 e 3 $(\mathrm{p}<0,001)$ (Tabela 6).

Quando o parâmetro testado foi a AC, houve diferença estatística entre os grupos do sexo masculino e do sexo feminino com o nível de significância (p) de 0,02, sendo valor encontrado maior no grupo do sexo masculino (Tabela 5).

Da mesma forma que o AND, a comparação do AC entre os grupos de diferentes faixas etárias demonstrou um diferença estatística $(\mathrm{p}=0,001)$, e o pós teste de Bonferroni evidenciou uma diferença estatística significante entre os grupos 1 e $2(\mathrm{p}=0,005)$, entre os grupos 2 e 3 ( $p=0,006)$ e muito significante entre os grupos 1 e 3 ( $p<0,001)$. (Tabela 6)

Tabela 5 - Tabela representando os p-valores para as variáveis AND e AC entre os diferentes sexos

\begin{tabular}{ccc}
\hline \multicolumn{3}{c}{ p-valor das variáveis AND e AC em relação ao Sexo } \\
\hline & & Feminino \\
AND & Masculino & $\mathrm{p}=0,03$ \\
AC & Masculino & $\mathrm{p}=0,02$ \\
\hline
\end{tabular}

Fonte: $\mathrm{O}$ autor

Tabela 6 - Tabela representando os p-valores para as variáveis AND e AC entre os diferentes grupos etários

\begin{tabular}{lcccc}
\hline \multicolumn{4}{c}{ p-valor das variáveis } & AND e AC em relação aos grupos etários \\
\hline \multirow{5}{*}{ AND } & Grupo 1 & Grupo 1 & Grupo 2 & Grupo 3 \\
AC & Grupo 1 & - & 0,001 & $<0,001$ \\
& & - & 0,005 & 0,006 \\
AND & Grupo 2 & - & - & 0,01 \\
AC & Grupo 2 & - & - & $<0,001$ \\
\hline \multicolumn{5}{l}{ Fonte: O autor }
\end{tabular}


Não houve diferença estatística quando comparados os resultados do NHE entre os grupos do sexo masculino e do sexo feminino $(\mathrm{p}=0,3)$. Não houve diferença estatística quando comparado os valores de NHE entre os grupos de diferentes faixas etárias $(p=0,79)$ (Tabela 7 e 8).

O parâmetro estudado ND não apresentou diferença estatística quando comparado os grupos do sexo feminino e do sexo masculino $(\mathrm{p}=0,12)$. (Tabela 7) No entanto, ao se comparar os valores de ND entre os grupos de faixa etária diferente, notou-se diferença estatisticamente muito significante $(\mathrm{p}<0,001)$. (Tabela 8).

Tabela 7 - Tabela representando os p-valores para as variáveis NHE e ND entre os sexos

\begin{tabular}{llc}
\hline \multicolumn{2}{l}{$\mathrm{p}$-valor das variáveis NHE e ND para o sexo } \\
\hline & & Feminino \\
NHE & Masculino & $\mathrm{p}=0,799$ \\
ND & Masculino & $\mathrm{p}=0,4$ \\
\hline
\end{tabular}

Fonte: $\mathrm{O}$ autor.

Tabela 8 - Tabela representando os p-valores para as variáveis NHE e ND entre os diferentes grupos etários

\begin{tabular}{lc}
\hline p-valor das variáveis NHE e ND para a idade \\
\hline & Idade \\
NHE & $p=0,395$ \\
ND & $p<0,001$ \\
\hline
\end{tabular}

Fonte: $\mathrm{O}$ autor. 
DISCUSSÃO 


\section{DISCUSSÃO}

Os resultados deste estudo demonstram que as relações do esterno com região de transição cervicotorácica da coluna vertebral apresentam diferenças quando comparados a dados previamente relatados. Estudos existentes sobre a relação do esterno com a coluna vertebral basearam-se em um número limitado de pacientes quando comparado a este trabalho (SHARAN; PRZYBYLSKI; TARTAGLINO, 2000; FRASER et al., 2002; KARIKARI; POWERS; ISAACS, 2009).

Foi possível observar estas as relações da transição cervicotorácica com o esterno foram medidas e analisadas com relação ao sexo e idade dos pacientes.

Para o cirurgião de coluna, prever a necessidade de se realizar uma osteotomia no esterno tem implicações diretas na escolha da via de acesso para tratamento de patologias que acometem a região de transição cervicotorácica da coluna vertebral, além de modificar os possíveis riscos cirúrgicos e morbidade pós-operatória do paciente. Por esta razão diversos grupos procuraram desenvolver métodos para tal propósito. Em 2000, Sharan, Przybylski e Tartaglino estudaram uma linha que tangencia a incisura supraesternal e uma linha que dividisse ao meio o disco intervertebral no plano sagital, e que foi denominada pelos pesquisadores de disco intervertebral mais distal visualizado acima do esterno. Os mesmos concluíram que não seria necessária a utilização de osteotomias no manúbrio/esterno quando ambas as linhas estivessem distais à patologia.

Em 2002, Fraser et al. compararam diversos parâmetros para auxiliar o cirurgião na escolha da via de acesso para tratamento das patologias que acometem a transição cervicotorácica. Os métodos utilizados apresentaram-se muito complexos e utilizavam de muita trigonometria. Isto dificulta a aplicação na prática, o que justificaria não termos encontrado nenhuma menção direta testando este método na prática. Em 2007, Lakshmanan et al. estudaram em exames de ressonância magnética de uma amostra de pacientes, a linha tangente ao manúbrio (NHE).

O objetivo deste trabalho foi determinar o nível passível de ser operado sem a necessidade de uma osteotomia no esterno. Por outro lado, baseados somente em exames de tomografia computadorizada, Karikari, Powers e Isaacs (2009) defenderam em seu estudo que somente a linha discal seria o suficiente para predizer a necessidade ou não de um procedimento cirúrgico de osteotomia no esterno. Neste trabalho os autores utilizaram como referência o método de Sharan, Przybylski e Tartaglino (2000), sendo o primeiro estudo que testou a aplicação clínica pré-operatória destes métodos. 
Em 2009, Teng et al. propuseram o ângulo cervicotorácico como método para a programação pré-operatória. O ângulo é formado por duas linhas, ambas com origem na incisura supraesternal nos cortes sagitais na linha média. Uma linha é traçada horizontalmente até o corpo vertebral adjacente, e a outra linha divide ao meio o disco intervertebral C7T1.Eles consideraram que para lesões localizadas acima deste ângulo, que não possui valor absoluto mas representa uma área de abrangência, não seria necessária a realização de osteotomias, lesões localizadas entre as linhas que formam esse ângulo poderiam não exigir a realização de osteotomias e lesões localizadas abaixo deste ângulo, exigiriam a realização de osteotomia no esterno durante o acesso cirúrgico. Apesar de não termos avaliado pacientes portadores de lesões na coluna vertebral, acreditamos que a utilização dos ângulos formados entre os corpos vertebrais (AC) ou discos intervertebrais (AND) e o esterno possam modificar a indicação da abordagem cirúrgica, uma vez que ângulos mais agudos poderiam dificultar o acesso às patologias e a colocação de implantes.

Em 2011, Falavigna, Righesso e Teles propuseram um método semelhante ao utilizado por Sharan, Przybylski e Tartaglino (2000). Os autores incluíram a avaliação pré-operatória do exame de ressonância magnética para a avaliação de anomalias vasculares que contraindicassem o procedimento cirúrgico. Foi defendido neste estudo a utilização de uma linha que tocasse a vértebra mais cranial para avaliar a necessidade de se realizar ou não uma esternotomia. Os autores defendem em que muitos casos este método pode por vezes aumentar a sensibilidade quanto à predição da realização de osteotomias no esterno, entretanto consideramos que, em muitos casos, a cifose torácica é um fator limitante importante quanto à viabilidade ou não da abordagem (FALAVIGNA; RIGHESSO; TELES, 2011).

Em 2016, Mai et al. utilizaram o método ND descrito por Sharan, Przybylski e Tartaglino (2000) em exames de ressonância nuclear magnética para testar sua eficácia na prática médica. Fica evidente que muitas tentativas foram feitas para a criação de um método de programação simples e com boa aplicabilidade clínica no tratamento das patologias da transição cervicotorácica.

É notório que o método descrito por Sharan, Przybylski e Tartaglino foi a base para a maioria dos estudos e que este apresentou boa aplicabilidade clínica. Esta foi a razão para a escolha deste método para este estudo, e pela fácil reprodutibilidade da técnica, nós utilizamos a mesma metodologia descrita por estes autores para a determinação do nível horizontal em relação ao esterno (NHE) e o nível discal (ND). 
Além de descrever métodos de avaliação, diversos estudos relataram seus achados nas populações estudadas. De acordo com Sharan, Przybylski e Tartaglino (2000) o ND localizouse em T2-T3 em 14,1\% dos pacientes estudados. Esses resultados foram bem semelhantes aos de Karikari, Powers e Isaacs (2009), que evidenciaram o ND em 17,3\% dos casos, e aos de Mai et al. (2016), que relataram o ND em T2-T3 em 16,1\% dos pacientes. Diferentes dos resultados encontrados em nosso estudo, que evidenciaram em apenas 1,6\% dos pacientes o ND em T2-T3 (Tabela 9). Semelhante ao nível T2-T3, o nível T1-T2 variou muito entre os estudos previamente reportados quando comparamos com nossos resultados. Enquanto os estudos prévios evidenciaram 59,4\%, 82,7\% e 62,2\% dos ND a partir de T1-T2, nossos resultados mostraram apenas $28,3 \%$ dos pacientes com o ND a partir deste nível.

Quando comparamos o ND encontrado em nosso estudo com os valores apresentados em outras populações, observamos que a amostra utilizada em nosso estudo apresentou um ND mais proximal, o que significa que poderia ser maior a necessidade de realização de uma osteotomia do esterno durante o acesso cirúrgico utilizado para o tratamento das patologias da transição cervicotorácica da coluna vertebral. Assim, a ND poderia estimar a porcentagem de pacientes em que seria possível uma abordagem cirúrgica acima do nível indicado sem a necessidade de osteotomias. (Gráfico 3).

Tabela 9 - Distribuição do parâmetro ND e a porcentagem de pessoas nas quais seria possível de se realizar uma cirurgia em diferentes estudos.

\begin{tabular}{|c|c|c|c|c|}
\hline $\begin{array}{l}\text { NÍVEL } \\
\text { DISCAL }\end{array}$ & $\begin{array}{l}\text { SUGINO e } \\
\text { HERRERO }\end{array}$ & $\begin{array}{l}\text { SHARAN, PRZYBYLSKI } \\
\text { E TARTAGLINO }\end{array}$ & $\begin{array}{l}\text { KARIKARI, } \\
\text { POWERS E ISAAC }\end{array}$ & MAI et al. \\
\hline C5-C6 & $100,0 \%$ & $100,0 \%$ & $100,0 \%$ & $100.00 \%$ \\
\hline C6-C7 & $96,6 \%$ & $99,0 \%$ & $99,4 \%$ & $92,7 \%$ \\
\hline C7-T1 & $74,3 \%$ & $95,2 \%$ & $91,7 \%$ & $85,5 \%$ \\
\hline T1-T2 & $28,3 \%$ & $59,4 \%$ & $82,7 \%$ & $62,2 \%$ \\
\hline T2-T3 & $1,6 \%$ & $14,1 \%$ & $17,3 \%$ & $16,1 \%$ \\
\hline T3-T4 & $0,0 \%$ & $0,0 \%$ & $0,0 \%$ & $0,0 \%$ \\
\hline
\end{tabular}

Fonte: $\mathrm{O}$ autor. 


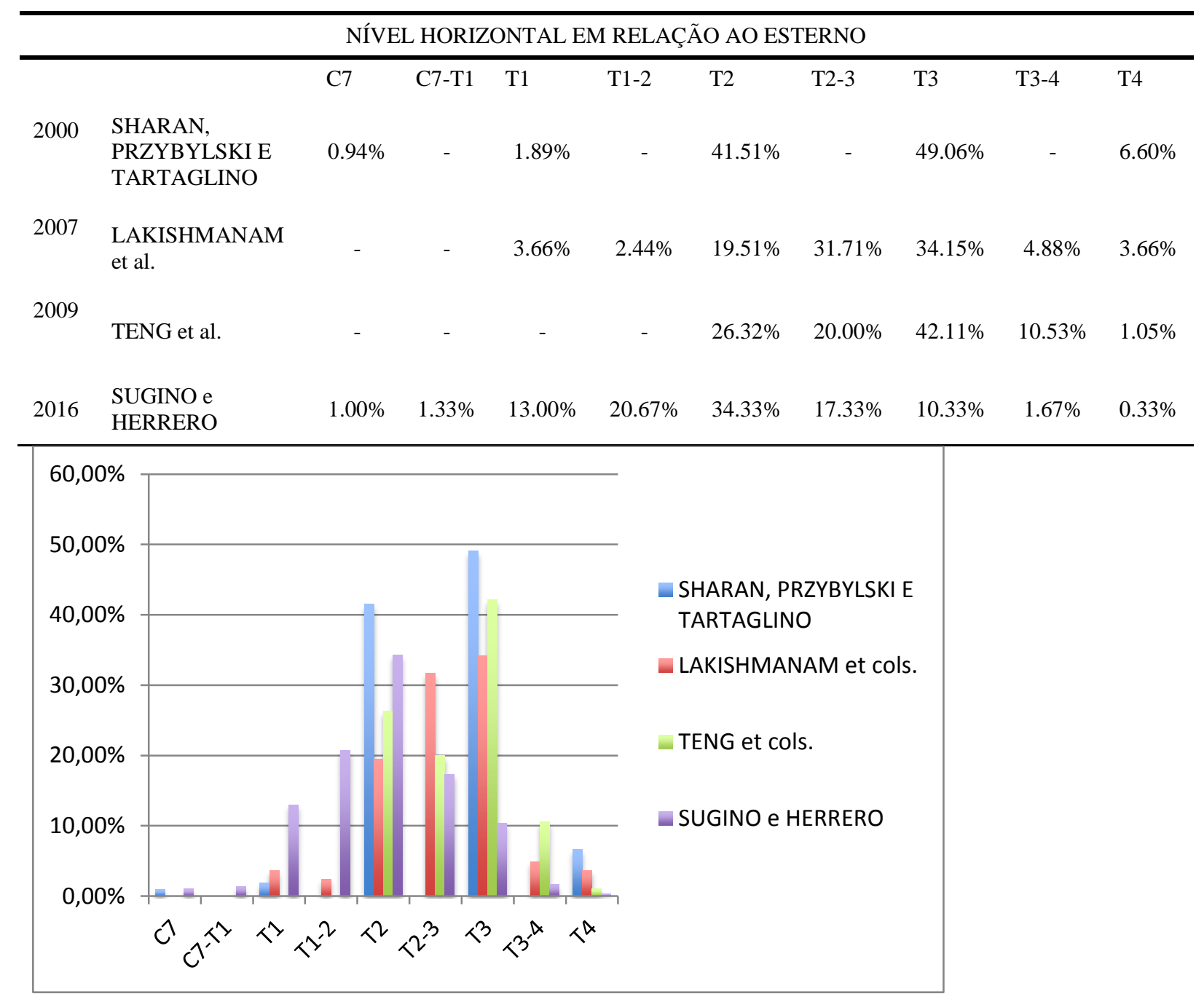

Gráfico 3 - Distribuição do parâmetro NHE e a distribuição dos casos por nível estudado e respectivo gráfico representando o mesmo parâmetro.

Fonte: $\mathrm{O}$ autor.

O NHE não apresentou diferença estatística quanto comparamos os resultados encontrados entre os grupos de diferentes faixas etárias ou sexo. Acreditamos que este resultado seja decorrente da característica linear da medida, ou seja, independe da angulação do corpo vertebral e discos intervertebrais. Deste modo o aumento natural da cifose torácica que ocorre com o avançar da idade não alteraria os resultados desta variável estudada. Assim, esta relação com o esterno seria fixa, não variando com a idade.

Os parâmetros AC e AND apresentam comportamento semelhante quando comparamos os resultados entre os grupos sexo e faixa etária. Encontramos valores superiores nos grupos do sexo masculino quando comparados aos grupos do sexo feminino. Foi evidente o aumento dos valores angulares nos grupos de faixa etária mais avançados com relação ao 
sexo e faixa etária. Acreditamos que uma explicação plausível para o fato desse aumento encontre-se no aumento dos valores angulares da cifose torácica, que ocorre com o envelhecimento normal, assim como evidenciado por Boyle, Milne e Singer (2002). Isso determinaria um aumento da angulação do segmento de transição cervicotorácica da coluna vertebral, corroborando com os achados de Park et al. (2015).

Os valores de ND encontrados neste trabalho variaram de acordo com a faixa etária. Os grupos de faixa etária mais avançados apresentaram valores menores de ND, ou seja, mais proximais em relação a coluna vertebral. Esse resultado segue o mesmo raciocínio aplicado para a análise do AC e AND, ou seja, com o aumento do valor angular da cifose torácica que ocorre de maneira fisiológica com o avançar da idade, e consequente aumento dos valores angulares do AND, um número menor de ND passaria acima do esterno. Podemos inferir com isso que conforme aumentamos a faixa etária, um número menor de patologias na coluna cervicotorácica seriam possíveis de serem abordados nesta amostra da população brasileira.

O estudo apresenta algumas limitações. Primeiro, todas as variáveis foram estudadas por um único pesquisador. No entanto, foi determinado que todas as avaliações fossem sempre realizadas utilizando-se de um mesmo computador e o mesmo programa. O desenho do estudo é retrospectivo e observacional, o que não permite confirmar sobre a real utilidade dos achados, por meio de uma avaliação clínica das técnicas utilizadas, uma vez que o método poderia modificar a interpretação da anatomia do paciente na avaliação pré-operatória. 
CONCLUSÃO 


\section{CONCLUSÃO}

Os nossos resultados, referentes a uma amostra da população brasileira, evidenciaram que o nível discal mais distal acessível com a realização de abordagem anterior à região cervicotorácica da coluna vertebral, sem a teórica necessidade de uma osteotomia do esterno, apresenta valores menores quando comparados aos dados previamente relatados atribuídos a outras populações. Em outras palavras, este achado pode ser traduzido como se os pacientes envolvidos no estudo apresentassem um menor número de vértebras passíveis de serem abordadas por meio de procedimento cirúrgico anterior sem a realização de osteotomia do esterno. Desta forma, o mesmo raciocínio pode ser aplicado para o nível horizontal em relação ao esterno, pois nossos resultados apresentaram valores mais craniais, comparados aos resultados de estudos prévios.

Além disso, o nível discal apresentou diferença quando comparamos os pacientes de diferentes faixas etárias, sendo que, quanto maior a faixa etária, menor foram os valores encontrados. Este achado representa uma migração para cranial do nível discal mais distal, conforme aumentamos a faixa etária dos pacientes estudados. 


\section{REFERENCIAS}

AMIN, A.; SAIFUDDIN, A. Fractures and dislocations of the cervicothoracic junction. J Spinal Disord Tech, v. 18, n. 6, p. 499-505, Dec 2005.

AN, H.S.; VACCARO, A.; COTLER, J. M. Spinal disorders at the cervicothoracic junction. Spine (Phila Pa 1976), v. 19, n. 22, p. 2557-64, Nov 1994.

BEUTLER, W. J.; SWEENEY, C. A.; CONNOLLY, P. J. Recurrent laryngeal nerve injury with anterior cervical spine surgery risk with laterality of surgical approach. Spine (Phila Pa 1976), v. 26, n. 12, p. 1337-42, Jun 152001.

BIRCH, R.; BONNEY, G.; MARSHALL, R. W. A surgical approach to the cervicothoracic spine. J Bone Joint Surg Br, v. 72, n. 5, p. 904-7, Sep 1990.

BOYLE, J. J.; MILNE, N.; SINGER, K. P. Influence of age on cervicothoracic spinal curvature: an ex vivo radiographic survey. Clin Biomech (Bristol, Avon), v. 17, n. 5, p. 3617, Jun 2002.

BOYLE, J. J.; SINGER, K. P.; MILNE, N. Morphological survey of the cervicothoracic junctional region. Spine (Phila Pa 1976), v. 21, n. 5, p. 544-8, Mar 11996.

CHARLES, R.; GOVENDER, S. Anterior approach to the upper thoracic vertebrae. J Bone Joint Surg Br, v. 71, n. 1, p. 81-4, Jan 1989.

CHEN, J.; EISMONT, F. J. Cervicothoracic trauma: diagnosis and treatment. Seminars in Spine Surgery, v. 17, n. 2, p. 84-90, Jun 2005.

CHOI, B. K.; HAN, I. H.; CHO, W. H.; CHA, S. H. Inferiorly migrated disc fragment at 1 body treated by t1 transcorporeal approach. J Korean Neurosurg Soc, v. 49, n. 1, p. 61-4, Jan 2011.

EVANS, D. K. Dislocations at the cervicothoracic junction. J Bone Joint Surg Br, v. 65, n. 2, p. 124-7, Mar 1983.

FALAVIGNA ASDRUBAL, R.O.; PINTO FILHO, D.R.; TELES, A. R.; KLEBER, F. D. Anterior approach to the cervicothoracic junction: case series and literature review Coluna/Columna, v. 8, n. 2, p. 153-160, Jun. 2009.

FALAVIGNA, A.; RIGHESSO, O.; TELES, A. R. Anterior approach to the cervicothoracic junction: proposed indication for manubriotomy based on preoperative computed tomography findings. J Neurosurg Spine, v.15, n.1, p. 38-47, Jul 2011.

FON, G. T.; PITT, M. J.; THIES, A. C., JR. Thoracic kyphosis: range in normal subjects. AJR Am J Roentgenol, v. 134, n. 5, p. 979-83, May 1980.

FRASER, J.F.; DIWAN, A.D.; PETERSON, M.; O'BRIEN, M.F.; MINTZ, D.N.; KHAN, S.N.; SANDHU, H.S. Preoperative magnetic resonance imaging screening for a surgical decision regarding the approach for anterior spine fusion at the cervicothoracic junction. 
Spine (Phila Pa 1976), v. 27, n. 7, p. 675-81, Apr 2002.

GIEGER, M.; ROTH, P. A.; WU, J. K. The anterior cervical approach to the cervicothoracic junction. Neurosurgery, v. 37, n. 4, p. 704-9; discussion 709-10, Oct 1995.

HALLER, J. M.; IWANIK, M.; SHEN, F. H. Clinically relevant anatomy of high anterior cervical approach. Spine (Phila Pa 1976), v. 36, n. 25, p. 2116-21, Dec 12011.

HERRERO, C. F. P. D. S.; PENNO, R. A. L.; DEFINO, H. L. Tratamento cirúrgico das doenças da transição cervicotorácica. Coluna/Columna, v. 8, n. 1, p.19-26, jan./mar. 2009.

KARIKARI, I. O.; POWERS, C. J.; ISAACS, R. E. Simple method for determining the need for sternotomy/manubriotomy with the anterior approach to the cervicothoracic junction. Neurosurgery, v. 65, n. 6 (Suppl.), p. E165-6; discussion E166, Dec 2009.

KNOLLER, S. M.; BRETHNER, L. Surgical treatment of the spine at the cervicothoracic junction: an illustrated review of a modified sternotomy approach with the description of tricks and pitfalls. Arch Orthop Trauma Surg, v. 122, n. 6, p. 365-8, Jul 2002.

KOOL, D. R.; BLICKMAN, J. G. Advanced Trauma Life Support. ABCDE from a radiological point of view. Emerg Radiol, v. 14, n. 3, p. 135-41, Jul 2007.

LAKSHMANAN, P.; AHMED, S.; AL-MAIYAH, M.; LYONS, K.; DAVIES, P. R.; HOWES, J.; AHUJA, S. et al. The low anterior cervical approach to the upper thoracic vertebrae: a decision by preoperative MR imaging. Diagn Interv Radiol, v. 13, n. 1, p. 30-2, Mar 2007.

LE, H.; BALABHADRA, R.; PARK, J.; KIM, D. Surgical treatment of tumors involving the cervicothoracic junction. Neurosurg Focus, v. 15, n. 5, p. E3, Nov 2003.

LE HUEC, J.C.; LESPRIT, E.; GUIBAUD, J.P.; GANGNET, N.; AUNOBLE, S. Minimally invasive endoscopic approach to the cervicothoracic junction for vertebral metastases: report of two cases. Eur Spine J, v. 10, n. 5, p. 421-6, Oct 2001.

MA, J.; WANG, C., ZHOU, X., ZHOU, S.; JIA, L. Surgical therapy of cervical spine fracture in patients with ankylosing spondylitis. Medicine (Baltimore), v. 94, n. 44, p.1-6, Nov 2015.

MAI, H.T.; MITCHELL, S.M.; JENKINS, T.J.; SAVAGE, J.W.; PATEL, A.A.; HSU, W.K. Accessibility of the cervicothoracic junction through an anterior approach: An MRI-based Algorithm. Spine (Phila Pa 1976), v. 41, n. 1, p. 69-73, Jan 2016.

MULPURI, K.; LEBLANC, J.G.; REILL, Y. C.W.; POSKITT, K.J.; CHOIT, R.L.; SAHAJPAL, V.; TREDWELL, S. J. Sternal split approach to the cervicothoracic junction in children. Spine (Phila Pa 1976), v. 30, n. 11, p. E305-10, Jun 2005.

NAZZARO, J. M.; ARBIT, E.; BURT, M. "Trap door" exposure of the cervicothoracic junction. Technical note. J Neurosurg, v. 80, n. 2, p. 338-41, Feb 1994.

NICHOLS, C. G.; YOUNG, D. H.; SCHILLER, W. R. Evaluation of cervicothoracic junction injury. Ann Emerg Med, v. 16, n. 6, p. 640-2, Jun 1987. 
PAL, G. P.; ROUTAL, R. V.A study of weight transmission through the cervical and upper thoracic regions of the vertebral column in man. J Anat, v. 148, p. 245-61, Oct 1986.

PANJABI, M. M.; DURANCEAU, J.; GOEL, V.; OXLAND, T.; TAKATA, K. Cervical human vertebrae. Quantitative three-dimensional anatomy of the middle and lower regions. Spine (Phila Pa 1976), v. 16, n. 8, p. 861-9, Aug 1991.

PARK, H.-Y.; LEE, S.-H.; PARK, S.-J.; KIM, E.-S.; LEE, C.-S.; EOH, W.; PARK, H. Y. Surgical management with radiation therapy for metastatic spinal tumors located on cervicothoracic junction: a single center study. J Korean Neurosurg Soc, v. 57, n. 1, p. 42-9, Jan 2015.

POINTILLART, V.; AUROUER, N.; GANGNET, N.; VITAL, J.M. Anterior approach to the cervicothoracic junction without sternotomy: a report of 37 cases. Spine (Phila Pa 1976), v. 32, n. 25, p. 2875-9, Dec 12007.

SAPKAS, G.; PAPADAKIS, S.; KATONIS, P.; ROIDIS, N.; KONTAKIS, G. Operative treatment of unstable injuries of the cervicothoracic junction. Eur Spine J, v. 8, n. 4, p. 27983, Aug 1999.

SIMON, S.L.; PAHL, M.A.; MARCOTTE P.J.; VACCARO, A.R.; GRADY, M.S. The management of infections involving the cervicothoracic junction. Seminars in Spine Surgery, v. 16, n. 3, p. 206-213, Sep 2004.

SHARAN, A. D.; PRZYBYLSKI, G. J.; TARTAGLINO, L. Approaching the upper thoracic vertebrae without sternotomy or thoracotomy: a radiographic analysis with clinical application. Spine (Phila Pa 1976), v. 25, n. 8, p. 910-6, Apr 2000.

TENG, H.; HSIANG, J.; WU, C. WANG, H.; WEI H.; YANG, X.; XIAO, J. Surgery in the cervicothoracic junction with an anterior low suprasternal approach alone or combined with manubriotomy and sternotomy: an approach selection method based on the cervicothoracic angle. J Neurosurg Spine, v. 10, n.6, p. 531-42, Jun 2009.

VANDEN HOEK, T.; PROPP, D. Cervicothoracic junction injury. Am J Emerg Med, v. 8, n. 1, p. 30-3, Jan 1990.

WANG, V. Y.; CHOU, D. The cervicothoracic junction. Neurosurg Clin N Am, v. 18, n. 2, p. 365-71, Apr 2007.

XIAO, Z. M.; ZHAN X.L.; GONG, D. F.; DE LI, S. Surgical management for upper thoracic spine tumors by a transmanubrium approach and a new space. Eur Spine J, v. 16, n. 3, p. 439-44, Mar 2007. 
ANEXOS 
Anexo A

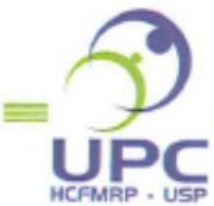

HOSPITAL DAS CLINICAS DA FACULDADE DE MEDICINA DE RIBEIRÄOO PRETO DA UNIVERSIDADE DE SĂO PAULO

www.hcrp.fmrp.usp.br

PROJETO DE PESQUISA

Ribeirão Preto, 10 de norembre $20 \quad 74$.

Ilustrissima Senhora

Dr. ${ }^{2}$ Marcia Guimarães Villanova

Sistema UPC $n^{\circ}$

8101

MD. Coordenadora do Comitê de Ética em Pesquisa

Do HCFMRP-USP e da FMRP-USP

Senhora Coordenadora,

Encaminho em anexo o projeto de pesquisa intitulado

Estudo morfométrio da colume vectebral triéciea

$\overline{-}$

juntamente com a documentação necessária para avaliação ética deste Comitê.

O projeto acima mencionado será desenvolvido no (a) depontemento de biemeca.

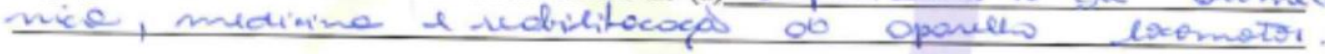

Informo também que o pesquisador responsável e o orientador possuem currículo Lattes.

$\mathrm{O}$ orçamento do presente projeto foi analisado pela equipe técnica da UPC antes da submissão ao Comitê foi Aprovadó

Equipe Técnica UPC

Atenciosamente,

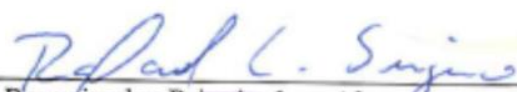

Pesquisador Principal ou Aluno (nome completo e assinatura)
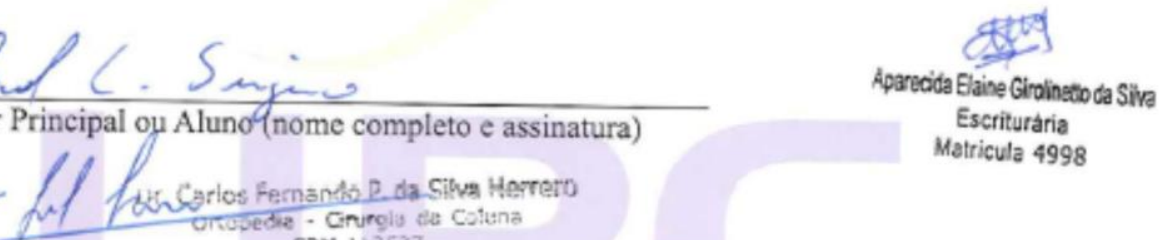

Pesquisador Principal ou Orientador (nome completo e assinatura)

\section{De acordo:}

Prok Dr. Clíudio Henrique Berblerí Profosser Tituis:

Chosic do Depto de Biomecânica, Med ens

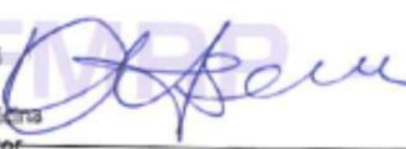

Chefredilepepartarmento (assinatura e carimbo)

Chefe do Ambulatório/ Laboratório (assinatura e carimbo)

Obs.: Caso algum chefe possua vinculo com a pesquisa, deverd ser solicitada assinatura do suplente.

Após assinatura cm todos os campos, digitalizar toda a doeumentaçào do check list e encaminhar ao CEP via Plataforma Brasil.

HC - Campus Universitário

Monte Alegre 14048-900 Ribeirăo Preto SP 


\section{Anexo B}

\section{PROJETO DE PESQUISA}

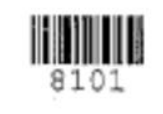

Ribeirão Preto,20 de FEVEREIRO de 2015.

HCFMRP - USP

Ilustríssima Senhora

Prof". Drª . Márcia Guimarães Villanova

MD.Coordenadora do Comitê de Ética em Pesquisa

Do HCFMRP e da FMRP-USP

Senhora Coordenadora,

Encaminho em anexo o projeto de pesquisa intitulado ESTUDO

MORFOMÉTRICO DA COLUNA VERTEBRAL TORÁCICA, juntamente com a documentação necessária para avaliação ética deste Comitê.

O projeto de pesquisa acima mencionado será desenvolvido no

departamento de DEPARTAMENTO DE BIOMECÂNICA, MEDICINA E

REABILITAÇÃO DO APARELHO LOCOMOTOR.

possuem currículo Lattes.

Informo também que o pesquisador responsável e orientador

O orçamento do presente projeto foi analisado pela equipe técnica da UPC antes da submissão ao Comitê e foi APROVADO.

Atenciosamente,

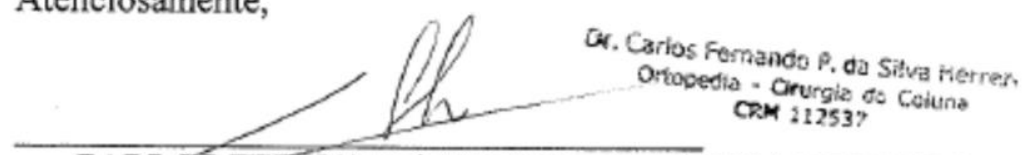

CARLOS FERNANDO PEREIRA DA SILVA HERRERO
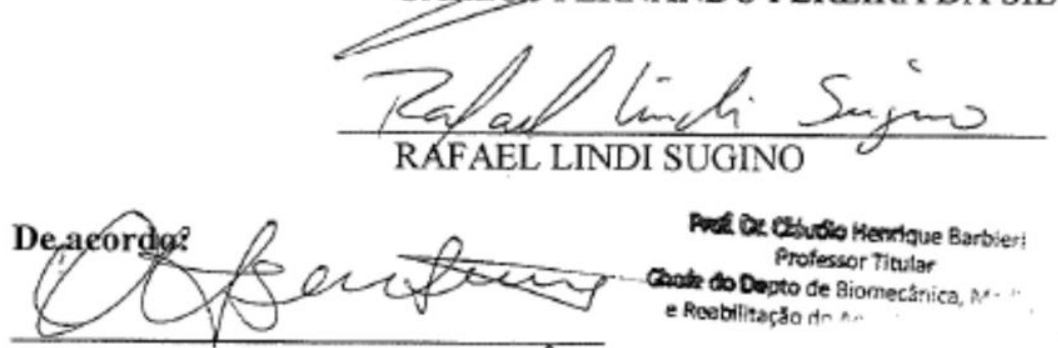

DEPARTAMENTO DE BIOMECÂNICA, MEDICINA E REABILITAÇÃ APARELHO LOCOMOTOR

Carimbar e Assinar

C. Prof pr. Antonio Carlos dos Santos

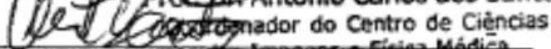

Chefe do Ambulatorio Acaberstaterio

Carimbar e Assinar

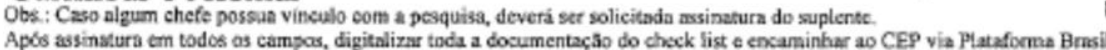

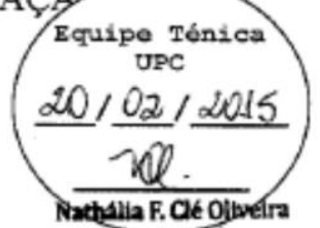

Escriturarta

Uaibade de Pesquisa Clinika-HCRP

Acos assinatura em todos as cámpas,

Matricula 6043 
Anexo C

\section{HOSPITAL DAS CLÍNICAS DA
FACULDADE DE MEDICINA DE
RIBP-RIBEIRÃO
RIBO PRETO DA USP -}

\section{PARECER CONSUBSTANCIADO DO CEP}

\section{DADOS DO PROJETO DE PESQUISA}

Título da Pesquisa: Estudo Morfométrico da Coluna Vertebral Torácica

Pesquisador: Carlos Fernando Pereira da Silva Herrero

Área Temática:

Versão: 3

CAAE: 42440615.7 .0000 .5440

Instituição Proponente: Hospital das Clinicas da Faculdade de Medicina de Ribeirăo Preto da USP . Patrocinador Principal: Financiamento Próprio

\section{DADOS DO PARECER}

Número do Parecer: 1.058 .123

Data da Relatoria: 30/04/2015

Apresentação do Projeto:

"O conhecimento da morfologia e anatomia das vértebras da coluna torácica, estruturas adjacentes, e suas variações são essenciais para a realização segura de procedimentos cirúrgicos neste segmento. Existem diversos estudos apontando para uma elevada taxa de parafusos mal posicionados, em especial na coluna torácica alta, local onde os pediculos são menores. Existem estudos que evidenciam uma diferença anatômica significativa da morfologia óssea das estruturas das vértebra torácicas em diferentes populações. No entanto, não existem até a presente data uma descrição desses parâmetros anatômicos da população brasileira. $O$ objetivo inicial desta pesquisa é averiguar se existe ou não tal diferença e criar uma base de parâmetros da normalidade para a populaçăo brasileira."

Objetivo da Pesquisa:

"Determinar os parâmetros anatômicos dos ossos da coluna vertebral torácica e compará-los aos resultados já apresentados na literatura, visando identificar e aprimorar as técnicas de inserçăo dos implantes pediculares utilizados no tratamento das afecções da coluna vertebral torácica."

Avaliação dos Riscos e Benefícios:

"Os riscos oferecidos aos pacientes participantes do estudo são a perda acidental da confidencialidade dos dados 6 a exposiçăo a radiação durante a realização do exame radiográfico, porém a avaliação raciológica foi solicitada previamente ao estudo para investigação de patologia

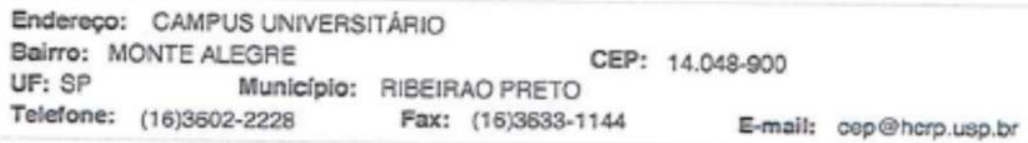




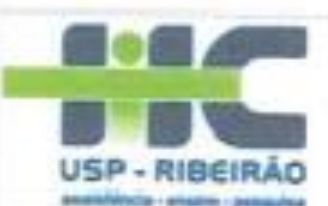

\section{HOSPITAL DAS CLÍNICAS DA FACULDADE DE MEDICINA DE RIBEIRÃO PRETO DA USP -}

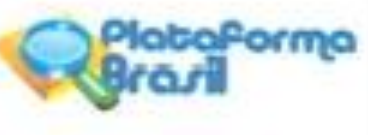

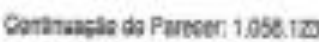

traumatica, năo relacionada com o estudo. Para manter 0 sigilo das informapbes dos pacientes, sardo utilizados apenas os dados de sexo e idade dos pacientes, assim como apenas os pesquisadores êtivolvidos no presente estudo terắ acesso aos exames." "Os resultados do estudo podern beneliciar todos 03 pecientes que forem submetidos a cirurgla da celuna ventebral toracika."

\section{Comentários e Considerap̧bes sobre a Pesquisa:}

O estudo alega que nấo serdio usados dados secundarios, mas bases de dados da unidade de saúde serầ consultadas para coleta de intormaç̧es de pacientes. Registro que tedas às vezes que um registro eletrdnico do paciente é acessado, flca registrado na unidade de saúce o log com o horario de acesso, local fisico (IR do computador), usuatrie que acasscu o registro. Dassa forma, tevo-se fer a mabima cautela com tais acessos a fim de que a contidencialidad 6 dos dados e a seguranç do sistema seja mantida.

Considerạ̧bes sobre os Termos de apresentaçāo obrigatórla:

Apresentcu cronograma, fiscos e bensticios e solictaçäo de dispensa do TCLE.

\section{Rscomendapбes:}

Nằ há.

Conelusóes ou Pendíncias e Lista de Inadequaptes:

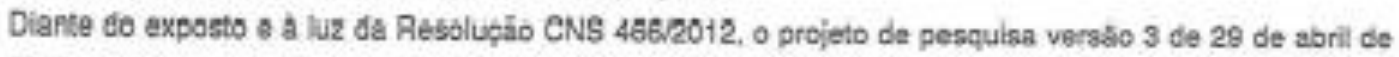
2015, assim como a dispenst do Tremo de Consentimento Livre e Eselafeeide, podsm ser anquacrados ina categoria APROVADO.

Situaģ:óo do Parecer:

Aprovado

Necessita Apreclạ̣ảo da CONEP:

N3o

Considerą̧óes Finais a crițío do CEP:

Projeto Aorovads: Tendb em vista a legislaçio vigente, devem sar encaminhados ao CEP, relatorios parciais gnuais referentas ae andamento da pesquias e relatcrio final ao término do trabalho. Qualquat modticaça do projeto original deve ser apresentada a este CEP em nova versijo, de forma objetivs e cem justificativas, para nova apreciş̧äo.

Enderepo: CANPUS UNWEAST APIO

Bairro; MONTE ALEGRE

UFI SP Matelpiot RIBEIRAOPRETO

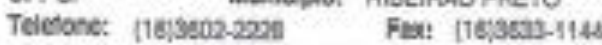

CEP! 42048.900

E-maih oepelnorpusp. Dt 


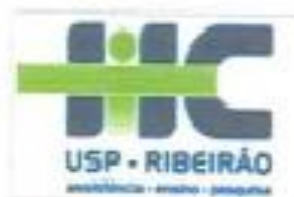

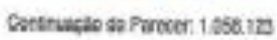

HOSPITAL DAS CLINICAS DA

FACULDADE DE MEDICINA DE RIBEIRÃO PRETO DA USP .

RIBEIRAO PRETO, 11 de Maio de 2015

Assinado por:

MARCIA GUIMARĹES VILANOVA

(Coordenador) 